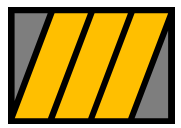

ESCUELA DE NEGOCIOS

Universidad Torcuato Di Tella

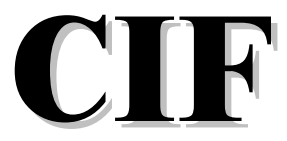

Centro de Investigación en Finanzas

Documento de Trabajo 04/2004

\title{
Prudential Responses for De Facto Dollarization
}

\author{
Alain Ize \\ International Monetary Fund \\ Andrew Powell \\ Universidad Torcuato Di Tella and World Bank
}
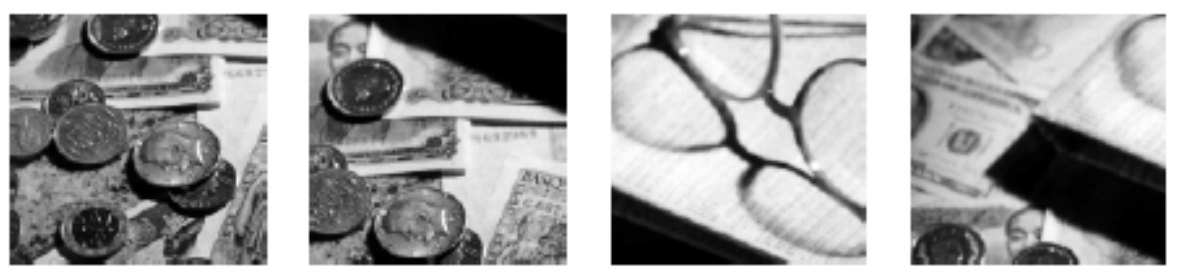

Miñones 2177, C1428ATG Buenos Aires - Tel: 4784.0080 interno 181 y 4787.9394 - Web site: www.utdt.edu/departamentos/empresarial/cif/cif.htm 


\title{
Prudential Responses to De Facto Dollarization
}

\author{
Alain Ize \\ IMF
}

\author{
Andrew Powell* \\ Universidad Torcuato Di Tella and World Bank
}

December 2003

\begin{abstract}
We develop a theoretical framework that encompasses four distinct motives for dollarization and discuss appropriate policy responses to help contain dollarization and its attendant risks. "Moral hazard" dollarization provides a clear case for prudential policy activism, including through the introduction of currency-specific prudential norms. However, prudential reform will have only a limited impact on dollarization when the main culprits are fear of floating and lack of monetary credibility. In such cases, a concerted and comprehensive reform agenda, including market oriented and institutional reforms, would be needed to shift the balance of risks in favor of the peso. While quantitative limits on dollarization could also be used to speed up dedollarization, risks could be high.
\end{abstract}

*This paper does not necessarily represent the view of the International Monetary Fund or the World Bank or any other institution. We would like to thank Giovanni Majnoni and Eduardo Levy Yeyati and participants and discussants at the pre-conference and conference on de-dollarization held at the InterAmerican Development Bank in October and December 2003 for valuable comments. All errors remain our own. Comments are welcome at aize@imf.org or apowell@utdt.edu 


\section{Introduction}

The importance of de facto financial dollarization for the soundness of financial systems has come to the fore in recent years in view of the continuing upward trend in dollarization in most regions of the world and in the wake of severe financial crises in Asia and South America where dollarization played an important role. Perceptions of de facto financial dollarization as a mostly unavoidable phenomenon, generally benign, and often beneficial to monetary stability and financial development in countries with limited currency credibility, have given way to more sobering thoughts. ${ }^{1}$ With the growing realization of the constraints financial dollarization imposes on monetary policy and the risks it imposes on the financial system, policy makers' attention has shifted towards finding ways to reverse dollarization or at least limit its drawbacks.

In this paper we explore whether (and which) regulatory interventions may be convenient to affect de facto dollarization and/or limit the attendant risks. When considering any regulatory intervention, there must be a prima facie case that there is some externality or problem to be corrected and secondly that the intervention will enhance welfare. Indeed, when dollarization is "good", policies aiming at limiting it may be counterproductive. Thus, to consider what interventions, if any, are appropriate we first need to understand why dollarization may occur and whether it is harmful. In doing so, the paper spans and brings together within a unifying framework a large body of recent literature on financial dollarization.

We identify four types of de facto dollarization. In a world without default, risk aversion and portfolio effects play the dominant role. By contracting in a mix of dollars and pesos, investors can limit their exposure to inflation and exchange rate volatility. We refer to this as "macroeconomic hedging dollarization". However, a number of additional factors can push dollarization beyond this base case. In particular, dollarization will rise when intermediating in pesos is more costly than intermediating in dollars, due to thinner or less efficient domestic currency markets or regulatory distortions that increase the cost of peso intermediation. ${ }^{2}$ We refer to this as "market imperfection dollarization". When borrower default is introduced, probabilities of default, rather than risk aversion, get the spotlight. The dollar dominates the peso if its value over different states of the world tracks more closely the debtor's earning flows, thereby limiting risk of default. The scope for dollarization increases with multiple creditors, as peso creditors get diluted by dollar creditors in devaluation-induced liquidations. We refer to such dollarization as "default dollarization". Our fourth and final case is when borrower default is so widespread that it may lead to bank default. If depositors are protected from counterparty risk by some insurance, contracting in dollars allows banks and their borrowers to get the upside of lower funding

\footnotetext{
${ }^{1}$ For a recent review of dollarization trends and risks, see De Nicolo, Honohan, and Ize (2003).

${ }^{2}$ Henceforth we will refer to local currency as "pesos" and foreign currency as "dollars". However, our arguments are as valid for all local and foreign currencies and indeed are also relevant for de facto euroization - a growing phenomenum in eastern europe.
} 
rates in the event of no devaluation while shifting the downside risk of a devaluation to the central bank or deposit insurance agency. We refer to this as "moral hazard dollarization".

Throughout this discussion, we examine the key role played by policy endogeneity. The inability of the authorities to precommit to allowing the exchange rate to depreciate and the desire to avoid a corporate or banking crisis gives rise to a "fear of floating" that lies at the core of the inefficient equilibria with excess dollarization. Fear of floating plus deposit insurance in both currencies encourages the private sector to use dollars. The end result may be a financial system in which the growth of dollar intermediation is punctuated by occasional but costly currency, corporate, and banking crises.

Based on the market failures and externalities identified in the first part of the paper, the rest of the paper then considers whether a prudential policy response is needed and if so what form it should take. As a general principle, a regulatory response should attempt to correct the distortion as close to its source as possible. Thus, prudential policy activism (such as higher capital requirements on dollar loans or a higher risk-adjusted premium on the deposit insurance for dollar deposits) is justified when there is a need to internalize risks that may otherwise not be internalized by market participants and where that intervention will result in an enhancement to welfare. The existence of multiple equilibria induced by fear of floating adds a level of complication. Extracting the economy from the "bad", high dollarization, low welfare equilibrium raises difficult issues of credibility and coordination between the monetary authorities, the supervisory authorities, and the public. The plan of the paper is as follows. Section II examines the roots of dollarization. Section III discusses policy implications. Section IV concludes.

\section{The Roots of Financial Dollarization}

\subsection{The model}

\subsubsection{The basic setting}

The economy is composed of identical atomistic depositors, (corporate) borrowers, and banks. It is subjected to random terms of trade disturbances such that

the equilibrium real exchange rate, $\widehat{\delta}$, fluctuates symmetrically around zero, its long run value. However, we assume that the actual real exchange rate, $\delta$, may deviate from this equilibrium level. Due to asymmetric price rigidities, real exchange rate undervaluations are immediately resolved through price increases, but real exchange rate overvaluations must be resolved through nominal depreciations. A reticence by the central bank in devaluing the exchange rate results in an over-valued exchange rate and hence a deviation from the real exchange rate equilibrium. Formally, when $\widehat{\delta}<0$, or $\widehat{\delta}>\delta^{M}>0$, where $\delta^{M}$ is a threshold real exchange rate beyond which the monetary authorities allow the exchange rate to float, $\delta=\widehat{\delta}$; instead, when $0<\widehat{\delta}<\delta^{M}$, the actual real exchange rate (as well as the nominal) remain constant, giving rise to a real overvaluation, $\widehat{\delta}$. 
We will assume that the economy faces at any time a symmetric, invariant, and uniform distribution of equilibrium real exchange rates in the range $\left[-\delta^{*}, \delta^{*}\right]$.

Several important disclaimers need to be made at this stage. First, the model is a one shot game albeit with several stages and is not dynamic. Thus, we do not model the potential build up over time of sucessive real exchange rate over-valuations. Second, to simplify the model, we focus on issues of currency composition for a given level of financial intermediation. The model is expressed in terms of a unit "slice" of financial intermediation (i.e., one dollar worth of intermediation) and we do not model the aggregate supply and demand for loanable funds nor capital. Hence, the model ignores the potentially important implications of tightening currency-specific prudential norms on the size of the financial system and output growth. Third, the model only deals with solvency risk and abstracts from liquidity risk. This leaves aside an important source of financial fragility and ignores the fact that dollarization may partly reflect the perception that dollars are more "liquid" than pesos under a crisis, i.e., "closer to the exit when the house is on fire" which may provide yet another explication of de facto dollarization.

\subsubsection{The depositors}

We assume that there are an infinite number of potential depositors who are risk averse and may invest in pesos or in dollars. ${ }^{3}$ Each atomistic depositor has a utility function of the type $U=E(r)-\frac{c}{2} \operatorname{Var}(r)$, where $E$ is the expectations operator, $\operatorname{Var}$ the variance operator, $c$ the degree of risk aversion, and $r$ is real financial income (for simplicity, we assume that non-financial income is zero). ${ }^{4}$ Deposit and loan contracts can be denominated in pesos or dollars. Depositors choose the share of deposits made in dollars, $\lambda_{D}$, in a non cooperative fashion based on expectations of inflation and currency risk and nominal interest rates offered on peso and dollar deposits, $r_{P}$ and $r_{D}$. Deposits are guaranteed by the government so that depositors do not face counterparty risk. ${ }^{5}$ Depositors also have access to foreign dollar deposits, so that $r_{D}=r_{D}^{*}$ at all times where $r_{D}^{*}$ is the foreign rate of interest. ${ }^{6}$

\footnotetext{
${ }^{3}$ Without loss of generality we assume that the initial nominal exchange rate is 1.

${ }^{4}$ Thus, we ignore the potential impact on dollarization of possible correlations between financial income and non financial income, including the safe haven benefits of the dollar when it depreciates at times of crisis and recessions. The paper by Chang and Velasco in this volume emphasizes some of these linkages.

${ }^{5}$ This assumption can be justified by the absence of a credible commitment technology that rules out bank bail outs. While expected bail outs lead to inferior welfare outcomes, due to moral hazard, governments end up bailing out banks in the event of large systemic shocks, due to political pressures and the adverse implications of widespread bank closures for the payments system.

${ }^{6}$ Notice that this assumption opens the possibility that the currency composition of deposits may differ from that of loans due to capital inflows or outflows. When deposit outflows to offshore accounts are not on-lent back to domestic borrowers by offshore banks, this creates a wedge that results in deviations from MVP. While Ize and Levy Yeyati (1998) examine this extension in their model, we will assume here for simplicity that any such external wedge remains sufficiently small so that it can be discarded in the analysis.
} 


\subsubsection{The borrowers}

There is also an infinite number of small potential borrowers (corporates). They are risk neutral and invest in a project whose real return, $\rho$, can fall below an "equilibrium rate of return", $\rho^{*}$, due to an exchange rate overvaluation: $\rho=\rho^{*}+\mu(\delta-\widehat{\delta})$, where $\mu \in[0,1]$ is the elasticity of the project's return with respect to the real exchange rate. ${ }^{7}$ Borrowers have a pledgeable capital $k^{C}$ per unit of investment which is assumed to be fully liquid and invested in riskless assets earning the risk-free real rate of return, $r^{*}$. They default when the average ex-post real cost of borrowing exceeds the real returns on the project and the capital associated with it. In the case of default, the remaining value of the project, net of the liquidation cost, $\varpi^{C}$, is distributed to the lenders (in this case the banks) on a pro-rata basis, based on the relative values of the claims at the time of the default. As borrowers are risk neutral they borrow in the currency with the lowest expected cost. When interest rate parity applies and costs are equalized across currencies, borrowers are indifferent to the currency composition of their loans. An interior solution for the degree of dollarization can then be obtained.

\subsubsection{The banks}

Banks borrow from depositors and lend to the corporates. They are small, risk neutral, competitive, and are subjected to a uniform capital adequacy requirement $k^{B}$ (we will examine the case of currency-specific capital requirements in the policy section). As in the case of the corporates, banks' capital is assumed to be invested in riskless assets earning the risk-free real rate of return, $r^{*}$. Banks set the borrowing interest rate in pesos and lending interest rates in both currencies. ${ }^{8}$ They take the currency composition chosen by depositors as given and are subject to regulation on open foreign exchange positions, implying that they should have no direct currency mismatch (however, we will relax this assumption when useful to the discussion). Perfect competition drives profits down so that the excess rate of return on capital over the risk-free rate, $r_{k}$, is equalized across the economy (i.e., it is the same for corporates and banks). Banks default on depositors (who are paid by the deposit insurance fund) when liabilities to depositors exceed banks' capital and the residual value of the loans (we assume that banks default only when corporates default). Bank defaults give rise to a liquidation cost $\varpi^{B}$.

\footnotetext{
${ }^{7}$ The parameter $\mu$ should reflect the degree of openess of the economy. In a more general model, the elasticities of output with respect to the equilibrium real exchange rate and the realized real exchange rate could differ, to reflect the contractionary or expansionary impact of a devaluation. See Cespedes, Chang, and Velasco (2002).

${ }^{8}$ An alternative assumption is that banks would set interest rates before depositors choose currency composition but taking into account the "reaction function" of depositors. Our equilibrium is the intersection of the reaction functions of depositors (how they set the degree of dollarization given interest rates) and banks (how they set interest rates given the degree of depositor dollarization) and subject to the "zero profit" condition.
} 


\subsubsection{The authorities}

We define the authorities as the Government, the Central Bank, the Bank Regulator and the Deposit Insurance Agency all rolled into one. ${ }^{9}$ The authorities set the exchange rate and the bank capital adequacy ratios. We will assume that only three items enter into the authorities' welfare function: the rate of return of projects (as a proxy for output), liquidation costs if projects are abandoned or banks liquidated, and an inflationary cost of abandoning the peg. The liquidation costs are those defined above, multiplied by a factor $b>1$, to account for the negative social externalities of large corporate or banking crises.

An important parameter in our model is the pass-through in prices that is expected after a devaluation (as we will see this parameter will determine a basic level of dollarization). We define $\nu^{*}$ as the structural pass-through associated with central banks that are strongly committed to price stability. ${ }^{10}$ Less committed central banks, or central banks that are perceived to be weak (such that the expected pass-through $\widehat{\nu}$ is above $\nu^{*}$ ) will generally validate in equilibrium the higher expected pass-through $(\nu=\widehat{\nu})$, as the output costs of maintaining price stability rise with $\widehat{\nu}^{11}$ In turn, the inflationary cost of a depreciation (i.e., the high pass-through) will discourage a central bank which is weak (or perceived to be weak) from depreciating the exchange rate. Thus, we assume the "inflationary cost" of reneging on the peg to be proportional to the expected pass-through, $a \widehat{\nu}$, where $a$ is a proportionality coefficient.

There are three regions over which welfare needs to be defined. For $-\delta^{*}<$ $\delta<0$, prices adjust immediately upwards to allow for the required real appreciation and there are no defaults nor changes in the monetary regime; hence $\delta=\widehat{\delta}$ and ex-post welfare is simply $W=\rho^{*}$. For $0<\delta<\delta^{M}$, the exchange rate becomes overvalued due to the absence of nominal exchange rate (or price) response; in the absence of defaults, welfare is $W=\rho^{*}-\mu \widehat{\delta}$; with corporate defaults it becomes $W=\rho^{*}-\mu \widehat{\delta}-b \varpi^{C}$; with corporate and bank defaults $W=\rho^{*}-\mu \widehat{\delta}-b \varpi^{C}-b \varpi^{B}$. Finally, when $\delta^{M}<\delta<\delta^{*}$ the exchange rate is allowed to depreciate to eliminate the overvaluation. In the absence of defaults, welfare is $W=\rho^{*}-a \widehat{\nu}$. With corporate and/or bank defaults, the respective liquidation costs need to be subtracted, and welfare becomes $W=\rho^{*}-a \widehat{\nu}-b \varpi^{C}$ or $W=\rho^{*}-a \widehat{\nu}-b \varpi^{C}-b \varpi^{B}$.

The authorities devalue when the welfare benefits of a devaluation exceed

\footnotetext{
${ }^{9}$ We will briefly discuss later what might change in the model if one (or more) of these institutions is made independent.

${ }^{10}$ In the absence of any "real dollarization" of nontradables and with full pass-through of exchange rates on the price of tradables, the structural pass-through would equal the share of tradables in the price level.

${ }^{11}$ Multiple, self-fulfilling, equilibria may thus exist, depending on the priors of the public as regards the type of central bank they face. This argument is similar in spirit to that in Cowan and Do (2003) where a "good" central bank finds that it is too costly to convince the market that it is not "bad", when the economy is dollarized. See also Gale and Vives (2002) who find that dollarization can have positive effects on credibility (by limiting the scope for time inconsistent policies) but can be undesirable when moral hazard effects dominate. To keep the model simple, we do not model here the post devaluation game nor do we attempt to endogeneize the link between actual and expected pass-through.
} 
the welfare costs, i.e., when the output gains, $\mu \delta^{M}$, exceed the output losses associated with the inflationary cost of the devaluation, $a \widehat{\nu}$, plus the liquidation costs when devaluations trigger corporate or bank defaults, $b \varpi^{C}$ and $b \varpi^{B}$, or minus these same liquidation costs when not devaluing is what triggers the defaults.

The timeline is as follows. In a pre-stage of the game we assume that bank capital and the deposit insurance regime is set. We also assume that private actors know the authorities' welfare function; hence, they understand that the exchange rate will be adjusted if the costs of lost output are sufficiently high. In the first stage of the game, depositors set deposit dollarization, $\lambda_{D}$, and banks set the peso deposit rate, $r_{P}$, and the peso and dollar lending rates, $R_{P}$ and $R_{D}$, and the authorities' devaluation trigger, $\delta^{M}$, is determined. These decisions are all assumed to be simultaneous. In the case of an interior solution, where the degree of dollarization is between zero and one, banks must set interest rates such that borrowers are indifferent between borrowing in dollars or in pesos. ${ }^{12}$ In the next stage, the uncertainty regarding the real exchange rate is realized shock and a devaluation occurs or not. Depending on the size of the shock and whether the devaluation has occurred, the corporates (and hence banks) repay loans if they can. If banks cannot repay depositors, the authorities repay depositors according to their original claims. ${ }^{13}$

\subsection{The dollarization map}

\subsubsection{The default thresholds}

In this subsection we develop a map of de facto dollarization depending on the realized value of the real exchange rate. The boundaries on this map are given by three critical schedules that define: i) when corporates default; ii) when banks default; and iii) when the authorities devalue. The equilibria of the game outlined above depend on the position of the default triggers in relation to the devaluation trigger.

Due to currency-induced credit risk, corporates will default as a result of a devaluation when:

$(1-\lambda)\left(R_{P}-\frac{\widehat{\nu}}{1-\widehat{\nu}} \delta^{C}\right)+\lambda\left(R_{D}+\delta^{C}\right)=\rho^{*}+k^{C}$,

or:

$$
\delta^{C}=(1-\widehat{\nu}) \frac{\rho^{*}+k^{C}-R}{\lambda-\widehat{\nu}}
$$

\footnotetext{
${ }^{12}$ We note that there is no information problem in this game. There is, however, a commitment problem. If the authorities could commit to a different monetary policy, they could move first (before depositors and banks choose the degree of dollarization). The outcome of the game would then be very different indeed. We also briefly discuss below what happens if the authorities cannot commit to a bank capital rule ex-ante.

${ }^{13}$ We do not then consider the possibility of the authorities lowering the value of depositors' claims through deposit securitization, pessification or other means.
} 
In the absence of a devaluation, corporates may default for two distinct motives. When the overvalued exchange rate, coupled with a high $\mu$, depresses the rate of return on the project leading to failure, default results from outputinduced credit risk. On the other hand, when the peso problem premium, coupled with the absence of a depreciation, raises the cost of peso funds, $R$, to an unsustainable level, default occurs as a result of interest rate-induced credit risk. In either case, the real equilibrium exchange rate trigger, $\widehat{\delta}^{C}$, is such that: $R=\rho^{*}-\mu \widehat{\delta}^{C}+k^{C}$, or:

$$
\widehat{\delta}^{C}=\frac{\rho^{*}+k^{C}-R}{\mu} .
$$

In the same vein, the (realized) exchange rate trigger for bank default if a devaluation occurs, $\delta^{B}$, is such that banks default when the cost of meeting their commitments to depositors, $(1-\lambda)\left(r_{P}-\frac{\widehat{\nu}}{1-\widehat{\nu}} \delta^{B}\right)+\lambda\left(r_{D}^{*}+\delta^{B}\right)$, equals their capital, $k^{B}$, plus the residual value of their claims on borrowers, $\rho^{*}+k^{C}-\varpi^{C}$, i.e., when:

$$
\varpi^{C}+(1-\lambda)\left(r_{P}-\frac{\widehat{\nu}}{1-\widehat{\nu}} \delta^{B}\right)+\lambda\left(r_{D}^{*}+\delta^{B}\right)=\rho^{*}+k^{B}+k^{C},
$$

or:

$$
\delta^{B}=(1-\widehat{\nu}) \frac{\rho^{*}+k^{B}+k^{C}-r-\varpi^{C}}{\lambda-\widehat{\nu}} .
$$

Similarly, the (equilibrium) exchange rate trigger for banks to default in the absence of a devaluation is $\widehat{\delta}^{B}$ such that: $\varpi^{C}+r=k^{B}+k^{C}+\rho^{*}-\mu \widehat{\delta}^{B}$, or:

$$
\widehat{\delta}^{B}=\frac{\rho^{*}+k^{C}+k^{B}-r-\varpi^{C}}{\mu} .
$$

Mapping out the various thresholds in the $(\lambda, \delta)$ space provides an immediate insight on how they interact (Figure 1). The $\delta^{C}$ and $\delta^{B}$ schedules have an asymptote for $\lambda=\widehat{\nu}$ which, as we shall show below, is the minimum variance portfolio (MVP) currency composition. They are negatively sloped; the range of $\delta$ 's which triggers a crisis increases with $\lambda$; i.e., more dollarized borrowers or banks are more vulnerable to currency-induced credit risk (see Appendix I). The $\widehat{\delta}^{C}$ and $\widehat{\delta}^{B}$ schedules are positively sloped (at least for $\lambda \leq \widehat{\nu}$, or for moderate degrees of risk aversion). This is due to the combination of the output and interest rate effects on credit risk. Due to the increasing impact of high nominal peso rates on the cost of funds, the range of $\widehat{\delta}$ 's which trigger a crisis rises as $\lambda$ falls; the more borrowers or banks contract in pesos, the more exposed they are to interest rate-induced credit risk. But a large real equilibrium exchange rate shock that leads to an overvaluation (i.e., is not accomodated through a depreciation) can also induce bankruptcies due to output losses (which affect both peso and dollar contracts). The more intense the fear of floating (the higher $\left.\delta^{M}\right)$, the wider the range of $\widehat{\delta}$ 's which triggers a crisis, hence the more exposed the economy to output-induced credit risk. It can be easily checked that the $\delta^{B}$ and $\widehat{\delta}^{B}$ schedules lie on the right of the $\delta^{C}$ and $\widehat{\delta}^{C}$ schedules, respectively, provided $k^{B}+(R-r)>\varpi^{C}$, i.e., if banks' capital (and intermediation margin) 
is sufficient to cover corporate liquidation costs. We will assume this to be the case.

\subsubsection{The devaluation threshold}

Assume, without loss of generality, that the $\widehat{\delta}^{C}$ schedule intersects the $\delta^{M}$ schedule below the $\delta^{C}$ schedule. Immediately below the $\delta^{C}$ schedule, there is therefore no risk of default for exchange rate shocks around $\delta^{M}$. Hence:

$$
\delta^{M}=\frac{a \widehat{\nu}}{\mu} .
$$

This "basic" fear of floating is a direct manifestation of lack of monetary credibility. A higher expected pass-through (less credibility) raises the depreciation threshold (i.e., it exacerbates the rigidity of the exchange rate arrangement) by raising the cost of stabilizing prices after a depreciation.

As $\lambda$ rises, the $\delta^{M}$ schedule eventually intersects the $\delta^{C}$ schedule if corporate capital is sufficiently low. At this point, the monetary authorities experience fear of floating as letting go of the exchange rate will induce a corporate crisis. Thus, due to corporate liquidation costs, the $\delta^{M}$ schedule then coincides with the $\delta^{C}$ schedule and $\delta^{M}$ rises, up to the point where the liquidation costs are exactly offset by the output benefits of a devaluation, i.e., when:

$$
\delta^{M}=\frac{a \widehat{\nu}+b \varpi^{C}}{\mu} .
$$

Beyond this point, the $\delta^{M}$ schedule becomes vertical again, until it meets the $\delta^{B}$ schedule. It coincides thereafter with the $\delta^{B}$ schedule, as the additional liquidation costs resulting from a banking crisis generate further fear of floating, and becomes vertical again at: ${ }^{14}$

$$
\delta^{M}=\frac{a \widehat{\nu}+b \varpi^{C}+b \varpi^{B}}{\mu} .
$$

Inversely, as dollarization declines below the $\delta^{C}$ schedule, the monetary authorities eventually start experiencing a "need for floating" where the $\delta^{M}$ and $\widehat{\delta}^{C}$ schedules intersect. To limit the amplitude of the region where a corporate crisis occurs, the $\delta^{M}$ schedule then coincides with the $\widehat{\delta}^{C}$ schedule and $\delta^{M}$ declines, up to the point where liquidation costs are offset by the output benefits of a devaluation, i.e., when:

$$
\delta^{M}=\frac{a \widehat{\nu}-b \varpi^{C}}{\mu} .
$$

\footnotetext{
${ }^{14}$ We will generally assume in the discussion $\delta^{M}(1)<\delta^{B}(1)$, so that a currency crisis always triggers a banking (and corporate) crisis in a fully dollarized economy. But this is not essential to the results of the paper.
} 
Further preference for floating is experienced when the $\delta^{M}$ schedule approaches the $\widehat{\delta}^{B}$ schedule. The $\delta^{M}$ schedule follows the $\widehat{\delta}^{B}$ schedule and turns vertical when:

$$
\delta^{M}=\frac{a \widehat{\nu}-b \varpi^{C}-b \varpi^{B}}{\mu} .
$$

The $\delta^{M}$ schedule is thus the jagged line represented in Figure 1. As dollarization increases, the monetary authorities experience increased fear of floating. Low dollarization leads to nearly floating rates; high dollarization to nearly pegged rates.

\subsubsection{Dollarization regions}

The three threshold schedules divide the $(\lambda, \delta)$ map in six regions. In Region I, on the left of the $\delta^{M}$ schedule and above the $\widehat{\delta}^{C}$ schedule, nothing happens; the exchange rate holds and there are no corporate nor banking crises. This resilience to crises is the product of moderate shocks, or high fear of floating, or low exposure to interest rate and output-induced credit risks. In Region II, on the right of the $\delta^{M}$ schedule but below the $\delta^{C}$ schedule, shocks are large but portfolio composition is close to MVP. There is a currency crisis, but neither a corporate nor a banking crisis. In Region III, on the right of the $\delta^{M}$ schedule and between the $\delta^{C}$ and $\delta^{B}$ schedules, shocks are large and dollarization largely exceeds MVP dollarization. Thus, the currency crisis triggers a corporate crisis (due to the impact of the devaluation on the cost of funds); however, banks are sufficiently capitalized to sustain the credit losses. In Region IV, on the right of the $\delta^{M}$ schedule and above the $\delta^{B}$ schedule, shocks are large and there is extreme excess dollarization, leading to a triple crisis: a devaluation triggers a corporate crisis, which in turn triggers a banking crisis. In Region V, on the left of the $\delta^{M}$ schedule and between the $\widehat{\delta}^{C}$ and $\widehat{\delta}^{B}$ schedules, the combination of moderate real exchange rate shocks and low dollarization leads to a situation in which the exchange rate holds but the output cost of the overvalued exchange rate and the high cost of funds trigger a corporate crisis. Finally, in Region VI, on the left of the $\delta^{M}$ schedule and below the $\widehat{\delta}^{B}$ schedule, dollarization is so low (and hence the cost of funds so high) that the collapse of the corporate sector triggers a banking crisis.

An increase in $\widehat{\nu}$ (i.e., an increase in expected pass-through) shifts the $\widehat{\delta}^{B}$ and $\widehat{\delta}^{C}$ schedules upwards by raising the ex-ante cost of peso funding. Thus, it broadens the scope for interest rate risk (it enlarges Regions V and VI). At the same time, by increasing fear of floating, it reduces the scope for currency risk (Regions III and IV shrink). An increase in $\mu$ similarly shifts the $\widehat{\delta}^{B}$ and $\widehat{\delta}^{C}$ schedules upwards and increases the scope for output risk by making projects more vulnerable to exchange rate overvaluations. Should this lead to $\widehat{\lambda}^{C}>\widehat{\nu}$, the MVP portfolio composition ceases to be default-free. In the other direction, should $\mu \rightarrow 0$, fear of floating would always dominate and the authorities would 
never devalue (except perhaps in the event of a liquidity crisis, an event which is outside our model but to which we will come back at the end of the paper). Thus, the assumption $\mu>0$ is critical to our model. On the other hand, as capital $\left(k^{B}\right.$ and $\left.k^{C}\right)$ increases, the $\delta^{C}$ and $\delta^{B}$ schedules shift in the north east direction and the $\widehat{\delta}^{C}$ and $\widehat{\delta}^{B}$ schedules in the south east direction, eventually disappearing from the map, i.e., the financial system becomes fully resilient to risk.

We will now explore the existence and properties of dollarization equilibria throughout this map. We will start by exploring equilibria in Regions I and II. Thereafter, we will explore equilibria in Regions III and V, at both extremes of the dollarization range, where corporate crises occur without a banking crisis. Finally, we will explore equilibria in the heavily dollarized, triple-crisis region (Region IV). We will only briefly refer to equilibria in Region VI.

\subsection{Macro dollarization}

Let us first explore the case in which the economy stays around MVP in Regions I and II. More specifically, we will explore equilibria around MVP under the assumption that $\hat{\lambda}^{C}<\widehat{\nu}$, i.e, MVP is free of output risk. It is then easy to show (see Appendix II) that the "reaction function" for depositors can be expressed as:

$$
\lambda=\widehat{\nu}+\frac{(1-\widehat{\nu})^{2}}{c V\left(\delta^{M}\right)}\left(r_{D}^{*}+\frac{P\left(\delta^{M}\right)}{(1-\widehat{\nu})}-r_{P}\right),
$$

or, in terms, of the peso-dollar interest rate spread:

$$
r_{P}-r_{D}^{*}=\frac{P\left(\delta^{M}\right)}{(1-\widehat{\nu})}+\frac{c V\left(\delta^{M}\right)}{(1-\widehat{\nu})^{2}}(\widehat{\nu}-\lambda),
$$

where $P\left(\delta^{M}\right)$ and $V\left(\delta^{M}\right)$ are the mean and the variance of the distribution of realized real exchange rates. With interest rate parity $\left(r_{P}=r_{D}^{*}+\frac{P\left(\delta^{M}\right)}{(1-\widehat{\nu})}\right)$ depositors choose the riskless, minimum variance portfolio. To tilt their portfolio towards dollars they must be offered a risk premium, $\frac{c V\left(\delta^{M}\right)}{(1-\widehat{\nu})^{2}}(\widehat{\nu}-\lambda)$. The higher the pass-through (the less credibility), the higher the inflation bubble resulting from an exchange rate adjustment. This raises the interest rate differential on account of both a higher expected inflation and a higher risk premium.

Since borrowers are risk neutral, for an interior solution we must have the following parity or arbitraje condition:

$$
R_{P}-R_{D}=\frac{P\left(\delta^{M}\right)}{1-\widehat{\nu}}
$$

And a zero excess profit condition for banking intermediation closes the model:

$$
R_{P}-r_{P}-C_{P}=R_{D}-r_{D}^{*}-C_{D}=r_{k} k^{B},
$$


where $C_{P}$ and $C_{D}$ are banks' unit intermediation costs in pesos and dollars, and $r_{k}$ is such that:

$$
\rho^{*}-r=r_{k}\left(k_{B}+k_{C}\right),
$$

$r$ being the real ex-ante cost of deposits.

In the absence of risk aversion $(c=0)$, and with uniform intermediation costs across currencies $\left(C_{P}=C_{D}\right)$, it is immediate from (10) that interest rate parity must hold for deposit rates and $\lambda$ becomes indeterminate; i.e., if agents only care about expected returns, which are equal across currencies, currency composition is irrelevant. However, the indeterminacy vanishes as soon as depositors exhibit any positive risk aversion, however small. Using (13) and (12) in (10) leads to the conclusion that, in the absence of default, the unconstrained deposit dollarization is the MVP allocation:

$$
\lambda=\widehat{\nu}
$$

and interest rates fulfill the interest rate parity conditions:

$$
\begin{aligned}
& r_{P}=r_{D}^{*}+\frac{1}{(1-\widehat{\nu})} P\left(\delta^{M}\right), \\
& R_{P}=R_{D}+\frac{1}{(1-\widehat{\nu})} P\left(\delta^{M}\right) .
\end{aligned}
$$

This result is the same as that obtained by Ize and Levy Yeyati (1998). ${ }^{15}$ It is expressed here for the special case of a "peso-problem" in which inflation and depreciation are perfectly correlated. ${ }^{16}$ Macro dollarization reflects the credibility and intent of monetary policy. Thus, where devaluations are expected to be nominal but not real $(\widehat{\nu} \rightarrow 1)$, ex-ante nominal peso rates should be very high $\left(r_{P} \rightarrow+\infty\right)$, leading to full financial dollarization $(\lambda \rightarrow 1)$. Inversely, when monetary policy is credible and devaluations are not expected to be accomodated, financial dollarization is limited to its minimum possible structural level $\left(\lambda=\nu^{*}\right) \cdot{ }^{17}$

The MVP allocation $(\lambda=\widehat{\nu})$ allows perfect hedging as gains on dollars in the event of a devaluation, $\lambda \delta$, are exactly offset by losses on pesos, $\frac{\widehat{\nu}}{1-\widehat{\nu}}(1-\lambda) \delta$; thus, the variance of returns is zero and the cost of borrowing is the risk-free rate of interest, $r^{*}$, which is invariant both to the devaluation outcome and the pass-through:

$$
r^{*}=r_{D}^{*}+P\left(\delta^{M}\right) .
$$

\footnotetext{
${ }^{15}$ The case for MVP macro dollarization finds broad empirical support. See Ize and Levy Yeyati (1998) and the more recent and comprehensive estimates in De Nicolo, Honohan, and Ize (2003) and Fernandez Arias and Levy Yeyati (this volume).

${ }^{16}$ In the more general model of Ize and Levy Yeyati, both the volatility of inflation and that of the real exchange rate (as well as their cross-corrrelation) affects the currency composition of the MVP portfolio.

${ }^{17}$ Notice, however, that financial dollarization could deviate from the pass-through in a model where inflation and devaluation risks are not perfectly correlated. See Ize and Parrado (2002).
} 
Provided the expected pass-through matches the actual pass-through (more on this below), the MVP portfolio protects borrowers and lenders from inflation and real exchange rate risk in the event of a devaluation in the same way as a price-indexed portfolio. In the rest of the paper, we will refer to the MVP basket as an MVP "composite currency".

Notice that banks and borrowers, being both risk neutral, could swap currency positions. For example banks could borrow in dollars and lend in pesos. As long as the system remains in an interior equilibrium (with no risk of debt default), the expected cost of the two currencies is the same and neither banks nor borrowers should care about how they allocate currency risk amongst each other. Hence, absent regulations that limit the scope for open positions, loan dollarization could differ from deposit dollarization.

\subsection{Market imperfection dollarization}

\subsubsection{Differential costs}

While remaining in the no default regions, let us briefly explore how market imperfections or regulatory distortions can lead to additional dollarization by introducing a wedge in intermediation costs across currencies. Using (12) and (13), (10) can be rewritten:

$$
\begin{aligned}
& \lambda=\widehat{\nu}+\frac{(1-\widehat{\nu})^{2}}{c V\left(\delta^{M}\right)}\left(r_{D}^{*}-R_{D}+R_{P}-r_{P}\right), \\
& \text { or: } \\
& \qquad \lambda=\widehat{\nu}+\frac{(1-\widehat{\nu})^{2}}{c V\left(\delta^{M}\right)}\left(C_{P}-C_{D}\right) .
\end{aligned}
$$

Thus, $C_{P}>C_{D}$ leads to dollarization in excess of MVP, $\lambda>\widehat{\nu}$. For example, lack of money market or bond market development in local currency may increase the cost for banks of maintaining liquid reserves. Poor monetary management, resulting in excessively volatile interest rates, or payment system deficiencies, resulting in a need for higher cash reserves, can have a similar effect. Regulatory distortions, such as high unremunerated reserves on local currency deposits in a context of high inflation may be yet another cause of higher spreads in local currency. ${ }^{18}$

\subsubsection{Capital account liberalization}

Capital account and financial market liberalization may also constrain local dollar spreads and result in higher spreads in local currency. Suppose for example that local banks compete with more efficient or less heavily regulated offshore banks that intermediate only in dollars, with intermediation spreads $s_{D}^{*}$ that are below those of local banks $\left(s_{P}=s_{D}>s^{*}\right) \cdot{ }^{19}$ Currency specialization

\footnotetext{
${ }^{18}$ Recent papers that emphasize the market imperfections foundations of dollarization include Catao and Terrones (2000) and Caballero and Krishnamurthy (2003).

${ }^{19} \mathrm{An}$ alternative view is that (on shore) dollar intermediation is more costly due to the lack of a lender of last resort in dollars. It is also obviously an assumption that foreign banks
} 
will then take place, with local banks only intermediating in pesos, and overall financial dollarization (including offshore intermediation) again exceeding the MVP allocation, as can be checked from (19), expressed in terms of spreads:

$$
\lambda=\widehat{\nu}+\frac{(1-\widehat{\nu})^{2}}{c V\left(\delta^{M}\right)}\left(s_{P}-s_{D}^{*}\right) .
$$

Notice that the increase in dollarization does not result from foreign bank competition per se, but from the asymmetry brought about by the fact that the more efficient (offshore) banks only intermediate in dollars.

Alternatively, if dollar and peso intermediation are joint products that cannot be offered separately, i.e., if local banks cannot become peso banks exclusively, they will need to continue intermediating in both currencies. Crosscurrency subsidization will then take place such that the average local spread is sufficient to accomodate the higher cost of intermediation, based on a higher peso spread: $(1-\lambda) s_{P}+\lambda s_{D}^{*}=s=C+r_{k} k_{B}$,

or:

$$
\lambda=\frac{s_{P}-s}{s_{P}-s_{D}^{*}} .
$$

The portfolio schedule equation (20) is the upwards sloping line in Figure 2. Point A is the MVP equilibrium $\left(\lambda=\widehat{\nu} ; s_{P}=s_{D}^{*}\right)$. The spread schedule $(21)$ is an upwards sloping hyperbola that intersects the horizontal axis at $s_{P}=s>s_{D}^{*}$ and the portfolio schedule at $s_{P}=\widehat{s}_{P}>s$. Point B is the equilibrium when local banks can become exclusive peso banks. Point $\mathrm{C}$ is the equilibrium with mixed currency intermediation. As it can be readily inferred from the figure, the wedge between local and foreign spreads and dollarization are both higher when banks need to intermediate in both currencies. ${ }^{20}$

\subsection{Default dollarization}

\subsubsection{The case of single creditors}

In this section we examine the case in which corporates borrow from only one bank and continue to assume that banks are sufficiently capitalized that they never default (there are no Regions IV nor VI). Yet, corporates can default (Regions III and V exist and extend all the way to the edges of the dollarization

cannot enter into the peso market, or if they do, for some reason they become as inefficient as domestic banks.

${ }^{20}$ Notice that in practice interest rate differentials between pesos and dollars seem to be more pronounced on the lending side than on the deposit side, i.e., while this model would predict a negative premium on peso deposit rates and no premia on the lending side, the opposite seems to hold in most highly dollarized countries. There generally is a much larger premium on the lending side than on the deposit side (peso lending rates-adjusted for devaluation expectations-are much higher than dollar lending rates while peso deposit rates are only moderately lower than dollar deposit rates). One possible explanation could be that risk aversion is more widespread among the smaller borrowers that are typically the recipients of peso loans than among peso depositors, who are often large enterprises and public sector entities. 
map). We will first consider the case in which loans need to be denominated either in dollars or in pesos (mixed currency, MVP loans are not feasible). Under peso borrowing (Region V), borrowers may default in the absence of a devaluation, due to the high cost of peso loans, but remain solvent with a devaluation, as price increases ease the debt servicing constraint. The reverse holds true under dollar borrowing (Region III); corporates can service their debt in the absence of a devaluation but default with a devaluation.

The options facing borrowers and banks can be illustrated graphically in a simple manner when there is no fear of floating and the depreciation threshold, $\delta^{M}$, is unique. The thick line in Figure 3 is the total project's debt servicing capacity over the $\left[0, \delta^{*}\right]$ range. It declines with $\delta$ and jumps back up at $\delta^{M}$. The $R_{P}$ line is the (real) ex-post cost of peso borrowing; it jumps down at $\delta^{M}$ and becomes downward sloping due to the inflationary effect of a devaluation. The dollar ex-post borrowing cost is also a broken line, with a jump at $\delta^{M}$ above corporates' debt servicing capacity.

Consider first the limit case of zero risk aversion and no liquidation costs. In the absence of risk aversion, the ex-ante cost of deposits in pesos and dollars is always the same. Thus, in the absence of liquidation costs, banks (borrowers) should be indifferent as to which currency to intermediate since the expected yield (cost) of loans is the same across currencies. This implies that lending rates must adjust so that the two shaded areas in Figure 3 are equal. In the event of no devaluation, peso borrowers default and peso lenders get the residual value of the loans, which is higher than what they would get in dollars. In the event of a devaluation, it is the other way around. Dollar borrowers default and dollar lenders get higher returns on their loans than what they would have got in pesos. From an ex-ante perspective, returns are the same and currency composition does not matter.

However, borrowers and lenders are no longer indifferent to currency composition when there is a positive cost of default. Lenders must then translate the expected liquidation costs in the terms of the loan contracts. As borrowers prefer the cheapest loans, they arbitrage against the currency with the highest expected liquidation costs, i.e., the currency that leads to the highest probability of default. ${ }^{21}$ Thus, the dollar (or any high dollarization currency mix within Region III with the same probability of default) is preferred when there is a low probability of devaluation $\left(\delta^{*}-\delta^{M}<\delta^{M}\right.$ ), while the peso (or any low dollarization currency mix in Region $\mathrm{V}$ with the same probability of default) is preferred in the inverse case of a likely devaluation $\left(\delta^{M}>\delta^{*}-\delta^{M}\right)$.

Once fear of floating is introduced, the potential for multiple equilibria becomes evident. If the economy is highly dollarized, fear of floating leads to a high $\delta^{M}$, validating the dominance of the dollar in Region III. Inversely, if the economy is entirely in pesos, the preference for floating induces a low $\delta^{M}$, validating the dominance of the peso over the dollar in Region $\mathrm{V}$.

That agents prefer dollar contracting to (nominal) peso contracting is reminiscent of Calvo and Guidotti's (1989) finding in the context of public debt that

${ }^{21}$ See Appendix III for a formal demonstration. 
the viability of nominal contracting in local currency shrinks drastically under expectations of severe inflation. The result extends here to the case of private contracts. The culprit is low monetary credibility (a high $\widehat{\nu}$ ), that makes the ex-ante cost of peso funding prohibitively high.

Let us now consider the case of MVP lending. Because it is perfectly hedged, an MVP portfolio is not exposed to currency risk. Moreover, because the MVP rate is real (not affected by inflation), MVP loans are not exposed to nominal interest rate-induced credit risk. ${ }^{22}$ Should MVP loans be default free under any $\delta^{M}$, the scope for equilibria at the two extremes of the dollarization range would disappear. Indeed, MVP loans would have the same expected interest cost as single currency loans but no liquidation costs. ${ }^{23}$ The dominance of the MVP equilibrium over pure peso or pure dollar equilibria is not a result of risk aversion. Instead, it reflects the fact that (real) MVP lending provides a better match for the real income stream of the projects, and, hence, limits the scope for jumps in the cost of debt servicing, thereby limiting risks of default.

However, MVP loans may be exposed to real interest rate-induced credit risk (the real cost of MVP funds rises with the peso problem premium) and to output-induced credit risk. Figure 4 illustrates. In the absence of a devaluation, corporates default for $\delta>\widehat{\delta}^{C}$, due to the output loss associated with an overvalued exchange rate. They are better off with dollars in the absence of a devaluation; with MVPs, in the presence of a devaluation. The currency with the lowest probability of default (compare $\delta^{*}-\delta^{M}$ to $\delta^{M}-\widehat{\delta}^{C}$ ) will therefore dominate. Highly dollarized loans may become preferable to MVP loans if fear of floating leads to a limit peso problem in which the probability of devaluing/defaulting under high dollarization is small.

This result is similar to Jeanne's (2002). Agents prefer dollar contracting because the dollar rises opportunistically with the return on the project, allowing borrowers and lenders to share more efficiently (in the sense of limiting liquidation costs) the value of the project over different states of the world. Indeed, should the project's debt servicing capacity be a flat horizontal line in Figure 4 $(\mu=0)$, dollar lending would not yield any additional value over MVP lending in the event of a devaluation. Hence, the dollar rate would equal the MVP rate and there would be no benefit from contracting in dollars.

The endogeneity of the exchange rate regime can give rise to welfare inferior equilibria. To see this, suppose that:

$$
\delta^{M}(1)-\widehat{\delta}^{C}(1)>\delta^{*}-\delta^{M}(1)>\delta^{M}(\widehat{\nu})-\widehat{\delta}^{C}(\widehat{\nu}) .
$$

When the economy is in a fully dollarized equilibrium, (output and real interest rate induced) credit risk is higher on MVP loans than (currency induced) credit risk on dollar loans. Thus, it is optimal for any bank in the dollar equilibrium to

\footnotetext{
${ }^{22}$ We implicitly assume here no discrepancy between the expected and actual pass-throughs; we will come back to this issue in the policy section.

${ }^{23}$ Any mixed-currency loans around MVP that is default free would be similarly preferable to a dollar loan or a peso loan. As long as risk aversion is zero, there exists an infinity of such equilibria, as discussed in Section 2.3 above.
} 
transact in dollars. Yet, should the economy be instead in the MVP equilibrium, with a lower $\delta^{M}$, credit risk on MVP loans would be lower than on dollar loans. Thus, while the MVP equilibrium is clearly welfare superior, the economy may remain stuck in the dollar equilibrium.

Consider finally the more general case with risk aversion. In this case, the expected cost of funds (deposits) is no longer the same across currencies when currency composition deviates from MVP. This clearly restricts no-default equilibria to the MVP equilibrium, as already discussed in Section 2.3. As regards default equilibria, the currency risk premium comes in as an additional factor affecting the choice of currency; the currency with the lowest probability of default will continue to be preferred only if this advantage is not more than offset by a higher risk premium (see details in Appendix III). Hence, very high risk aversion will force all dollarization equilibria to converge to MVP.

\subsubsection{The case of multiple creditors}

Consider now the case of multiple creditors. Dollarization may result in this case from the fact that the opportunistic rise in the value of the dollar under a depreciation strengthens the claims of dollar creditors at the expense of peso creditors. ${ }^{24}$ Consider the case of the marginal peso creditor bank. The returns it obtains on a peso loan in the case of default are diluted by the fact that the residual value of the project is distributed on a prorata basis among all banks according to the value of their claims after the devaluation. Thus, a marginal peso lender when everybody else is in dollars would only obtain a diluted return $\frac{R_{P}}{R_{D}+\delta}=\frac{1+P(\delta) / R_{D}}{1+\delta / R_{D}}$. The main driving factor is no longer the likelihood of default but its correlation with the probability of devaluation. Should the probability of default be highly correlated instead with the maintenance of the peg, peso creditors would then be clearly better off. In this case, a marginal dollar lender would only obtain a fraction $\frac{R_{D}}{R_{P}}=\frac{1}{1+P(\delta) / R_{D}}$ of the returns obtained by a peso lender.

Thus, multiple creditor settings accentuates the bias towards multiple equilibria at both extremes of the dollarization range. When a default is tied to a devaluation (as in Region III), a systematic wedge is introduced in favor of the dollar, eliminating the possibility of lending in pesos at the margin when other creditors are in dollars. Although MVP lending would be default free and welfare improving if all creditors stuck to it, coordination failures may prevent it. Hence, a good MVP equilibrium may coexist with a bad dollar equilibrium. The externality comes from the fact that by sharing the same residual value of the project, the terms of each individual debt contract affect the conditions under which all other contracts are established. ${ }^{25}$ Such coordination failures are

\footnotetext{
${ }^{24}$ Papers emphasizing this channel of dollarization include Aghion, Bacchetta and Banerjee (2001) and Chamon (2001).

${ }^{25}$ While debtors would have in principle an incentive to maintain their debt in MVPs, the costs inherent in such coordination (including monitoring costs to verify compliance) may be too large to make it practical.
} 
of course more likely to be a concern for large borrowers. ${ }^{26}$

\subsection{Moral hazard dollarization}

\subsubsection{Basic setting}

To conclude, let us consider the case where banks are undercapitalized and, hence, exposed to default. Moral hazard can then provide a potent additional force for deviating from the MVP equilibrium, towards full dollarization. ${ }^{27}$ In view of the implicit guarantees on dollar loans, intermediating and borrowing in dollars allows banks and corporates to benefit from cheaper financing in the event of no devaluation and to walk away and leave the bill to the government in the case of a devaluation. As in the case of multiple creditor lending, inefficient dollarized equilibria can thus arise.

For simplicity, let us start again with the simpler case in which there is no risk aversion and banks are required to maintain a balanced open foreign exchange position (we will relax later both of these assumptions). We will assume that there exists a Region IV and that the MVP equilibrium is risk-free $\left(\widehat{\lambda}^{C}<\widehat{\nu}\right)$. As shown in Appendix IV, for full dollarization to be a stable equilibrium, one must show that a marginal bank has no incentives to change the currency composition of its portfolio from dollars to MVPs, which leads to the following condition:

$$
P\left(\delta^{M}(1)\right)>\frac{\delta^{*}-\delta^{M}(1)}{2 \delta^{*}}\left(k^{B}+k^{C}+\rho^{*}-r_{D}^{*}\right) .
$$

This condition indicates that dollar intermediation will be preferred when expected profits from borrowing at the lower dollar rate $\left(P\left(\delta^{M}(1)\right.\right.$ equals the spread between the MVP and the dollar deposit rates) more than offset the expected capital (and profitability) loss to banks and their borrowers in the event of a devaluation (the left hand side term). In other words, it pays to bet on no devaluation. Alternatively, replacing $P\left(\delta^{M}(1)\right)$ by its expression in (35), this can also be written:

$$
k^{B}<\left(r_{D}^{*}+\frac{\delta^{M}(1)+\delta^{*}}{2}\right)-\left(\rho^{*}+k^{C}\right)
$$

Banks will intermediate in dollars when their capital is insufficient to meet their expected liabilities to depositors in the event of a devaluation (including the full valuation losses deriving from the devaluation), net of the residual value of

\footnotetext{
${ }^{26}$ We would thus expect large corporations to borrow primarily (if not exclusively) in dollars while small borrowers are more likely to remain in pesos. This may at least partly explain the market segmentation in which the dollar is the currency of choice for large loans while the peso maintains an edge in the small retail market.

${ }^{27}$ Recent papers that emphasize government intervention as a source of free insurance against currency risk include McKinnon and Pill (1999), Dooley (2000), Schneider and Tornell (2000), and Burnside, Eichenbaum and Rebelo (2002). Broda and Levy Yeyati (2003) emphasize the moral hazard resulting from a deposit insurer. Chamon and Hausmann (2002) present a model with multiple equilibria where dollarization and monetary policy interact in a way which is very similar to the model presented here.
} 
their claims on corporates. This condition provides the basic justification for risk-based prudential activism, as we will see in the next section. ${ }^{28}$

Consider now the opposite case where the financial system as a whole is in the MVP equilibrium. It is easy to show (see Appendix IV) that the condition for the marginal bank to have no incentive to switch its intermediation to dollars now becomes:

$$
k^{B}=\left(r_{D}^{*}+\frac{\max \left\{\delta^{B}(1), \delta^{M}(\widehat{\nu})\right\}+\delta^{*}}{2}\right)-\left(\rho^{*}+k^{C}\right) .
$$

Putting together (24), and (25) leads to:

$\left(r_{D}^{*}+\frac{\max \left\{\delta^{B}(1), \delta^{M}(\widehat{\nu})\right\}+\delta^{*}}{2}\right)-\left(\rho^{*}+k^{C}\right)<k^{B}<\left(r_{D}^{*}+\frac{\delta^{M}(1)+\delta^{*}}{2}\right)-\left(\rho^{*}+k^{C}\right)$.

Thus, for very low levels of bank capital (below the lower bound of the condition above), moral hazard totally eliminates the possibility of having an equilibrium at MVP. Instead, full dollarization is the only possible equilibrium. Inversely, sufficiently high levels of bank capital (above the upper bound) bring moral hazard under control, to the point where full dollarization is no longer a stable equilibrium. In the intermediate range that satisfies (26), there are multiple equilibria. Since $\delta^{B}(1)<\delta^{M}(1)$, the key condition for multiple equilibria to exist is of course $\delta^{M}(\widehat{\nu})<\delta^{M}(1)$, i.e., "fear of floating" as reflected in a positively sloped $\delta^{M}$ schedule. A more dollarized economy leads to a more rigid exchange rate which, by enhancing moral hazard, induces dollarization, therefore closing the circle.

\subsubsection{Some extensions}

Three extensions are worth exploring at this stage. Consider first the case of risk averse depositors. There should now be a negative premium on the MVP interest rate as dollarization exceeds MVP, making MVP intermediation more attractive. While the minimum bank capital needed to rule out the high dollarization equilibrium is unaffected by the degree of risk aversion, for sufficiently high levels of risk aversion full dollarization is no longer a corner solution. Instead, there continues to exist a stable high dollarization equilibrium but at less than full dollarization. This equilibrium approaches MVP as risk aversion increases (see Appendix IV).

Second, let us briefly examine what would be the implications of relaxing banks' balanced open currency position. By swapping positions between them

\footnotetext{
${ }^{28}$ Since a marginal change in the currency composition of loans by the marginal bank has no impact on the likelihood of default by either the bank or its borrowers (the full dollarization equilibrium lies in the interior of Region IV), the marginal bank should have no incentive to change marginally the currency composition of its lending towards MVPs. Nor should the marginal bank have an incentive to switch the currency composition of a marginal borrower to dollars, since that raises credit risk and exposes them to liquidation costs which they must fully bear (a marginal change in the composition of their lending does not affect their default decision).
} 
and their borrowers, banks can maximize their own exposure to currency risk (i.e., maximize the option value of the government guarantee) while limiting the exposure of their borrowers. Should there be a depreciation, only the banks (but not the corporates) would fail. The benefit to corporates of not losing their capital would be reflected in higher rates of interest on their loans. Thus, both banks and corporates would benefit (see Appendix IV).

Third, as shown in Appendix V, fully pessified Region VI equilibria may dominate MVP (or fully dollarized) equilibria when the pass-through is sufficiently high and there is limited fear of floating. In this case, banks and corporates are effectively betting on a devaluation; should it fail to materialize, they default and let the government assume the high peso deposit rates. Moreover, in the absence of regulations, banks would fully shorten the peso, i.e., borrow in pesos and lend in MVPs so as to shield the corporates from default. Notice, however, that the full symmetry in this model between fully dollarized and fully pessoized equilibria, which follows from assuming the probability distribution of real exchange rate shocks to be time-invariant, is unlikely to be observed in practice. In a more realistic setting, the probability of a new maxi-devaluation this period given that the exchange rate was devalued last period should be low while the probability of the exchange rate continuing to hold this period given that it held last period should remain high. Thus, the benefits of lending in pesos should be short-lived while those of lending in dollars should linger on, explaining why dollarized equilibria dominate on average.

\section{Implications for prudential policies}

\subsection{When is a regulatory response appropriate?}

In the section above we have derived a "dollarization map" that includes three sources of credit risk and four distinct motives for de facto dollarization. ${ }^{29}$ The map characterizes equilibria in terms of the degree of dollarization and the associated monetary policy response. The motives for de facto dollarization are a mixture of macroeconomic and microeconomic incentives. The feedback from de facto dollarization to monetary policy creates the possibility of multiple equilibria and can be thought of as a type of negative externality. Agents do not take into account the effect of their decisions on policy makers. At the same time, policy makers, by assumption, are unable to commit to a monetary policy ex-ante. Thus, an equilibrium is obtained where the monetary authorities pursue the monetary policy that is optimal given the degree of de facto dollarization and private agents select the degree of de facto dollarization that is appropriate given their own individual incentives and taking monetary policy as given.

The appropriate prudential response will depend on the particular type (or combination) of de facto dollarization a country is experiencing. As a general rule, a regulatory response should only be called for when there are externali-

\footnotetext{
${ }^{29}$ The three sources of credit risk are output risk, real interest rate risk, and currency risk. They all stem from the single source of uncertainty regarding the real exchange rate.
} 
ties or market distortions that need to be corrected. In such cases, the response should address the underlying problem as close as possible to its source. However, the endogeneity of the monetary regime creates the possibility of multiple equilibria and hence particular difficulties. We will review each source of dollarization in turn.

\subsection{Macro dollarization}

The MVP portfolio provides a perfect hedge for depositors. In addition, by preventing currency mismatches for corporates, it shields them from currency risk (at least as long as expected and actual pass-throughs coincide; more on this below). Thus, in the absence of a credibility gap, macro dollarization clearly constitutes an optimal response to the macroeconomic environment and no regulatory response is called for. Indeed, this is the case where dollarization is "good" and attempts to eradicate it would be detrimental to welfare.

However, the macroeconomic environment may include a high expected passthrough, reflecting the central bank's inability to commit (or signal its commitment) to price stability. If so, measures that reduce $\widehat{\nu}$ (approximate it to its structural value) would be welfare enhancing. Indeed, in the context of the model presented above, welfare is given by:

$$
W=\frac{1}{2 \delta^{*}}\left[\int_{-\delta^{*}}^{0 *} \rho^{*} d \widehat{\delta}+\int_{0}^{\delta^{M}}\left(\rho^{*}-\mu \widehat{\delta}\right) d \widehat{\delta}+\int_{\delta^{M}}^{\delta^{*}}\left[\rho^{*}-a \widehat{\nu}\right] d \widehat{\delta}\right]
$$

where $\delta^{M}=\frac{a \widehat{\nu}}{\mu}$. It is easy to show that $W$ is a decreasing function of $\widehat{\nu}$. A higher expected pass-through affects welfare negatively because the authorities do not devalue quickly enough (the negative term in the second integral) and incur deeper output or inflationary costs if the exchange rate is devalued (the negative term in the third integral).

An adequate policy response would thus consist in taking measures aimed at demonstrating the central bank's commitment to (and capacity to deliver) price stability. Such measures could include a strengthening of the fiscal accounts or the financial system's soundness (depending on whether fiscal dominance or financial system vulnerabilities are the key determinants of the weak monetary policy), or, more generally, measures aimed at consolidating actual (not just legal) central bank independence, such as the introduction of inflation targeting. By removing underlying pressures for monetization, clarifying the central bank's goals, enhancing its accountability, limiting its exposure to pressures towards attaining other goals (including avoiding financial system turmoil), and overtly increasing its commitment to low inflation (hence the penalty for failing to deliver), such measures should enhance the overall credibility of monetary policy and push the economy gradually towards lower dollarization and lower expected pass-through equilibria. 


\subsection{Market dollarization}

The second motivation for dollarization stems from what we refer to as "market imperfections". De facto dollarization according to this motivation would, in the first instance, also be an optimal response to the institutional and regulatory environment. The use of the dollar increases efficiency from a micro perspective as it enhances liquidity or implies greater efficiency in financial intermediation. Yet, a policy response may be called for on broader welfare grounds, as the higher dollarization induced by market imperfections can have undesirable externalities, such as enhanced fear of floating and a more vulnerable financial system.

Making dollar intermediation more costly would clearly not constitute a first best response. It might reduce dollarization but at an unacceptably high cost in terms of financial disintermediation. However, if the distortions results from excessive regulations on peso intermediation, removing or fully remunerating reserve requirements on local currency deposits would serve to eliminate a bias against the local currency, which may be particularly damaging when inflation is high. On the other hand, if the problem is one of thin peso markets, made even thinner by dollarization, ways should be found to give them greater depth. Measures to promote the development of peso instruments and markets, such as improving day-to-day monetary management (thereby limiting the volatility of overnight peso interest rates), facilitating payments in local currency, developing a market for local currency public securities, developing price-indexed instruments (see below), or even subsidizing intermediation in pesos would constitute appropriate responses.

\subsection{Default dollarization}

\subsubsection{Is a risk-based prudential approach appropriate?}

In the case of single creditor default dollarization, it is optimal for banks and corporates to choose dollar contracting if the probability of default under dollar contracting is lower than that under the alternative currency (peso or MVP). In this case, welfare is given by:

$$
W=\frac{1}{2 \delta^{*}}\left[\int_{-\delta^{*}}^{0 *} \rho^{*} d \widehat{\delta}+\int_{0}^{\delta^{M}}\left(\rho^{*}-\mu \widehat{\delta}\right) d \widehat{\delta}+\int_{\delta^{M}}^{\delta^{*}}\left(\rho^{*}-a \widehat{\nu}-b \varpi^{C}\right) d \widehat{\delta}\right]
$$

where: $\delta^{M}=\frac{a \widehat{\nu}+b \varpi^{C}}{\mu}$. Comparing this expression with the welfare of the MVP equilibrium, as depicted above, it is clear that there are now two additional costs - the potential cost of corporate default in the crisis region (the third integral) and the enhanced fear of floating (higher $\delta^{M}$ ) leading to higher output distortions (the second integral).

The heart of the problem is a "coordination failure" between the private sector and the monetary authorities. While peso (or MVP) lending might be default free under a peso (or MVP) equilibrium, it may be heavily exposed to 
credit risk in an equilibrium with high de facto dollarization and high fear of floating. This can be seen in Figure 5. Under a fully dollarized equilibrium, a marginal bank assessing the credit risk associated with dollar versus MVP loans would compare the width of the range $\left[\delta^{M}(1), \delta^{*}\right]$, that determines the probability of default on dollar loans due to currency risk, to the width of the range $\left[\delta^{M}(\widehat{\nu}), \delta^{M}(1)\right]$, that determines the probability of default on MVP loans resulting from interest rate and output risk. Should the former exceed the latter (i.e., the case shown in Figure 5), it would conclude that dollar lending is less risky, hence preferable; yet, should all banks switch to MVP loans, fear of floating would decline from $\delta^{M}(1)$ to $\delta^{M}(\widehat{\nu})$, making MVP loans risk-free, hence clearly preferable. If the timeline of the model could be altered, with the monetary authorities setting monetary policy credibly before private agents determine the degree of dollarization, then the problem might be solved. ${ }^{30}$ Similarly, in the case of multiple creditors, the coordination failure between the creditors would be resolved if the correlation between currency risk and default risk could be reduced, i.e., by exiting the limit peso problem equilibrium and getting rid of fear of floating.

While dollar lending subjects the economy to risks of corporate crises and unduly ties the hands of the monetary authorities, it is important to note, however, that banks are fully internalizing risks from a microeconomic perspective. They are lending in dollars (rather than in pesos or MVPs) precisely because it is less risky to do so in a highly dollarized, high fear of floating environment. Therefore, absent a change in monetary policy and dollarization, requiring banks to hold more capital would be counterproductive. The more banks have to lose, the more they will stick to the less risky dollar credits. Thus, risk-based prudential instruments are clearly not part of the solution.

\subsubsection{Dedollarizing by fiat}

Instead, there are two alternative routes to ensure coordination and extract the economy from the bad equilibrium; an approach based on financial repression and one based on shifting the balance of risks. The most extreme variation of the first approach would include pessifying the entire existing stock of dollars upfront (the "just do it" approach). While such a move would have the advantage of speeding up the transition (and hence limiting potential transition costs), it would probably conflict with the goal of enhancing the credibility of the central bank. Moreover, by eliminating all forms of dollarization, good and bad, it would surely have detrimental welfare effects. Progressively tighter quantitative restrictions on dollar lending might be less traumatic than up-front pessification, but could have similar efficiency costs. A more market friendly approach would consist in introducing a temporary tax-subsidy scheme that favors the peso and penalizes the dollar. For example, dollar deposits could be subjected to unremunerated reserve requirements, the proceeds of which could be used to remunerate reserve requirements on peso deposits at above market rates.

\footnotetext{
${ }^{30}$ This could be shown formally changing the sequential structure of the game and giving the monetary authority a type of Stackelberg leadership role.
} 
However, a common drawback of all approaches seeking to penalize or prohibit the use of the dollar is that it could induce a substantial (or massive) disintermediation from onshore banks to less repressed (and regulated) onshore or offshore intermediaries. Yet, if the dollar remains the unit of choice in intermediation (whether onshore or offshore), borrowers would continue to be exposed to currency risk. Hence, fear of floating would remain. Thus, the danger is that such actions might provoke an even worse equilibrium in which intermediation is diverted offshore (with all the attendant negative implications this has for bank supervision and general financial system soundness), yet overall dollarization (and hence fear of floating) remains unchanged.

\subsubsection{Changing the balance of risks and costs in favor of the peso}

The difficulties of a compulsory approach raise the issue of what might work better. When risks of regulatory arbitrage are important, exiting the bad dollarized equilibrium may require alternative measures that change the balance of risks (or costs) banks are facing in favor of the peso (or MVP). This can be done through measures that reduce fear of floating (i.e., make the dollar more risky) or facilitate the use of the peso and make the peso less risky.

Measures in the first category would include steps to enhance central bank independence and enhance its commitment to low inflation, as already described earlier. Other desirable changes in the institutional environment could include reforms of the bankruptcy code. ${ }^{31}$ By saving corporates from costly liquidation in the context of a systemic crisis and, hence, limiting liquidation costs, such reforms could help reduce fear of floating. ${ }^{32}$ The multiple creditor coordination problem could possibly be resolved in a contractual way. ${ }^{33}$

Measures in the second category would include measures that promote less risky peso alternatives to the dollar (such as price-indexed peso instruments), enhance the development of peso money and bond markets, and facilitate the use of derivatives and other hedging instruments. The development of price indexation appears to be a particularly promising option for countries that face a deep credibility gap. ${ }^{34}$ In particular, attempting to develop a local currency public bond market when there is little appetite for local currency instruments may come at a high fiscal cost. Price indexed instruments have several advan-

\footnotetext{
${ }^{31}$ The case for a more lenient bankruptcy code to borrowers in the event of a systemic crisis has been made by Miller and Stiglitz (2000). Indeed, if the crisis is systemic, individual owners or managers may be less to "blame". Secondly, in the context of a systemic crisis, where the capital of good firms and banks may also be reduced, the externalities of corporate defaults across the economy would surely be more costly. Our results suggest a third justification, based on the interaction between dollarization and monetary policy.

${ }^{32}$ We do not suggest this as an ad hoc ex post measure but rather as a measure to be included explicitly ex ante. We also note that to the extent that such measures are already expected despite no explicit legislation to this effect, then this type of dollarization may be less serious than previously thought.

${ }^{33}$ Peso contracts with suitable acceleration clauses could protect seniority in bankruptcy as much as dollar contracts but with better risk sharing characteristics.

${ }^{34}$ Of course there has to be confidence in the index adopted and that there would be no gaming in how it was calculated.
} 
tages over MVPs. First, they do not require that loans be made in a composite currency, which may be impractical, particularly for the smaller loans. Second, they do not rely on an abstract notion of expected pass-through, which may be fuzzy for the public at large and may vary from person to person. Third, unlike MVP returns, returns on price-indexed instruments are not exposed to the risk of incorrect perceptions or unexpected changes in policies, i.e., to the risk that realized and expected pass-throughs may actually differ. ${ }^{35}$

The introduction of price-indexed instruments should not permanently displace nominal peso instruments. Instead, provided the monetary authorities are able to stabilize inflation, indexation might be seen as a mid-way station towards the full use of nominal contracts (i.e., "nominalization"). Once the economy is in the MVP equilibrium, the move from price-indexed peso instruments to nominal peso instruments becomes easier. In addition to directly reducing the risk of peso instruments, through limiting fear of floating, the move to MVP can enhance the credibility of monetary policy, reducing the expected pass-through $\widehat{\nu}$ and further limiting exposure to interest rate risk in the peso region. ${ }^{36}$

\subsection{Moral hazard dollarization}

\subsubsection{How much bank capital is needed?}

The case of moral hazard dollarization fits squarely within the realm of a traditional prudential response. Indeed, moral hazard is central to bank regulation and drives much of the complex web of regulation and supervision that we see today. The usual response to moral hazard is to ask banks for more capital such that bank owners are risking more of their own money and less of somebody else's. ${ }^{37}$

In the model outlined above, the amount of bank capital required to eliminate the bad equilibrium and switch to a default free equilibrium (in case it

\footnotetext{
${ }^{35}$ The real MVP ex-post rate of interest is a function of the difference between the actual and expected pass-throughs: $r=(1-\widehat{\nu})\left(r_{P}-\frac{\nu}{1-\nu} \delta^{M}\right)+\widehat{\nu}\left(r_{D}^{*}+\delta^{M}\right)=(1-\widehat{\nu}) r_{P}+\widehat{\nu} r_{D}^{*}+\frac{\widehat{\nu}-\nu}{1-\nu} \delta^{M}$. Or, using (16), $r=r_{D}^{*}+P\left(\delta^{M}\right)+\frac{\widehat{\nu}-\nu}{1-\nu} \delta^{M}$.

${ }^{36}$ Targeting nominal (rather than indexed) interest rates for day-to-day monetary policy can also facilitate the switch towards nominal instruments at the short end of the yield curve. See Fuentes et al (2003) for the case of Chile. The dominance of price-indexed instruments over nominal instruments at the longer maturities may be more difficult to phase out. However, retaining long maturity price-indexed instruments should not be a significant problem. Quite to the contrary, the existence of such instruments could generally be welfare improving.

${ }^{37} \mathrm{~A}$ standard result in the literature is that capital requirements should be related to systemic risk. Imposing non risk sensitive capital requirements may make banks invest more in risky assets and divest from those where the capital requirement does not bind potentially making a regulated bank more risk; see Kim and Santomero (1988). In theory bank capital requirements should be made sensitive to the "systemic risk" or the "beta coefficient" of an asset, and not to a simple measure of its risk like its standard deviation; see Freixas and Rochet (1999). In practice such policies are limited by problems of monitoring. Introducing limited liability makes things worse; the basic conclusion in this case is that, when moral hazard is key, bankers will behave more prudently simply if more of their money is at stake. Rochet (1992) argues that even capital requirements related to systemic risk do not reduce banking risk effectively. Instead, he argues in favour of an additional minimum level of capital, independent of risk.
} 
exist) is given by (24). Setting aside corporate liquidation costs (which are not included in this condition because they do not affect the shareholders of failing banks), this condition might be thought of in terms of a value at risk capital adequacy rule. In the case of this model, a value at risk rule (which implies that the regulator sets a statistical tolerance in terms of a maximum probability of bank failure) maps to a maximum devaluation that banks would have to absorb, $\delta_{\text {var }}$.

Should the supervisory authorities' risk tolerance be in the range $\delta^{M}(1)<$ $\delta_{v a r}<\frac{\delta^{M}(1)+\delta^{*}}{2}$, this would shift the $\delta^{B}$ schedule past the devaluation trigger point. Thus, concerns for banking crises would no longer be the binding factor on monetary policy and fear of floating would decline to a level commensurate with only corporate (but not banking) crises. In turn, the decline in fear of floating would lower the risk associated with peso (or MVP) loans, thereby increasing their attractiveness (see below). Nonetheless, the moral hazard-induced high dollarization equilibrium would continue to exist. Should risk tolerance be even stricter, such that $\delta_{v a r}>\frac{\delta^{M}(1)+\delta^{*}}{2}$, then (24) indicates that such a rule (which would incorporate liquidation costs) would lead to a level of bank capital that would eliminate the high dollarization equilibrium.

To get some feel for the quantitative implications, replace $\rho^{*}-r_{D}^{*}$ by $r_{k}\left(k^{B}+\right.$ $k^{C}$ ) using (14), and rearrange terms in (24), leading to:

$$
k^{B}+k^{C}>\frac{\delta_{v a r}}{1+r_{k}} .
$$

Assume $\delta_{v a r}=\frac{\delta^{M}(1)+\delta^{*}}{2}$ is 50 percent and $r_{k}$ is 10 percent. ${ }^{38}$ Hence, total capital should be at least 45 percent. If corporate capital is 33 percent, this would give a bank capital of only 12 percent, which is surprisingly small. However, capital here is the pledgeable capital effectively lost by corporates that default, which may be substantially less than balance sheet capital. While we have tried to account for this in our low figure for corporate capital (developing country leverage ratios tend to be low), there could be a relatively high standard error attached to this figure.

Moreover, a number of additional factors would need to be considered in assessing the overall feasibility and costs of extracting the economy from the high dollarization equilibrium. First and foremost, notice that the above calculation (and the feasibility of extracting the economy from the bad equilibrium) assumes that the alternative equilibrium is default free. This might not be the case. As long as the economy remains dollarized, fear of floating might continue to induce substantial interest rate and output-induced credit risk in the MVP equilibrium. Moreover, should the peso (rather than MVP) be the only practical alternative to dollar intermediation, the scope for nominal interest rate-induced credit risk under the peso equilibrium could become very high. Should risk exposure remain

\footnotetext{
${ }^{38}$ The assumption here is then that a $50 \%$ devaluation includes a high percentage of the distribution corresponding to the statistical tolerance value of the VAR methodology - Basel II for example uses a tolerance value of $99.9 \%$ (ie: a $0.1 \%$ probability of a bank exhausting its capital) to calibrate the so-called Internal Rating Based approach.
} 
higher with pesos than with dollars, more capital would simply not work, or could be counterproductive, as already discussed. Furthermore, even if credit risk is marginally less important on peso loans than on dollar loans, it would take a much larger amount of capital to convince banks to switch (when comparing the two currencies, banks would see that the odds of losing their capital would be nearly the same; yet, the dollar would retain the advantage of lower interest costs under good states of the world).

In addition, the calculation above also assumes that banks effectively lose their capital in the case of a banking crisis. Yet, the moral hazard argument could be pushed to a further extreme. If banks do not expect to lose their capital and expect compensation of one form or another, then the effectiveness of capital requirements in moderating moral hazard is reduced. ${ }^{39}$

On the other hand, once the economy returns to the new peso (or MVP) equilibrium, the amount of bank capital needed to ensure the stability of this equilibrium would be lower (see equation 25). Thus, if the country is patient enough (in terms of a high enough discount factor and assuming that policy makers have sufficiently long term objectives), it might be worthwhile to pay the possible transition costs (in terms of financial disintermediation) associated with the temporarily higher level of bank capitalization.

\subsubsection{Alternative risk-based prudential approaches}

Based on a definition of $\delta_{v a r}$, i.e., the maximum depreciation that supervisors wish banks to be able to withstand, the supervisor could request that banks hold additional capital or else that they increase their general provisioning requirements. Either option should have a very similar impact on banks' risk management. In a Basel I-type framework, provisions may allow for a finer, loan-by-loan calculation of reserves, depending on the particular characteristics of the loan and the borrower. However, where a devaluation is perceived to be a large but unlikely event, it is more natural that these additional reserves be capital rather than provisions. Basel II (revised) approaches, that are calibrated to cover the whole value at risk derived from both expected and unexpected losses (up to a specified tolerance value), provide substantial flexibility as to how the overall required reserve is constituted. Thus, for a regulator who wishes to follow Basel II, market-related credit risks can be accounted for in what is referred to as Pillar II (extra requirements for "other risks" subject to national regulatory discretion) or through provisioning. ${ }^{40}$

Whether the required reserves are made through capital or provisions, it stands to reason that they should be related to the risk associated with lending in each currency, i.e., their levels should be currency specific. For countries that will not follow Basel II's advanced approaches, a simple rule that Basel I

\footnotetext{
${ }^{39} \mathrm{~A}$ further assumption, of course, is that capital requirements can be effectively enforced ex ante.

${ }^{40}$ However, very few developing countries are likely to implement the more advanced approaches of Basel II that include currency aspects of default probabilities, at least in the near future.
} 
type capital requirements should be currency specific may represent a practical alternative. As shown in Appendix IV, this introduces a new term in (24) when the excess rate of return on capital, $r_{k}$, is positive, i.e., when capital has a positive opportunity cost; in this case, the condition determining the choice of intermediation currency becomes:

$$
k_{D}^{B}+\frac{2 \delta^{*}}{\delta^{*}-\delta^{M}(1)} r_{k}\left(k_{D}^{B}-k_{m}^{B}\right)>\left(r_{D}^{*}+\frac{\delta^{M}(1)+\delta^{*}}{2}\right)-\left(\rho^{*}+k^{C}\right) .
$$

where $k_{D}^{B}$ and $k_{m}^{B}$ are the capital requirements on dollar and MVP intermediation, respectively. As $k_{D}^{B}$ is increased there are now two effects affecting the choice of currency: i) a "stock" effect reflecting the cost of losing capital in the event of a devaluation; and ii) a flow effect reflecting the cost of holding additional capital in the event of no depreciation. Notice that the effectiveness of the flow effect rises with the cost of capital and declines with the probability of a devaluation.

To put some numbers on this, suppose that there is a $3 \%$ probability of devaluation, and that the opportunity cost of capital is $10 \%$ for both corporates and banks. Then, a $2 \%$ differential in capital requirements would have the same impact as a $(10 / 3) * 2=6.7 \%$ increase in the stock of capital. However, this flow effect is only effective to the extent that the cost of capital is above the risk-free rate and devaluation risks are limited. When banks expect to be fully compensated and the market for bank capital is efficient, the opportunity cost of capital may be low; hence, the impact of differential capital requirements will be reduced. ${ }^{41}$

An alternative to different capital requirements would be to introduce riskadjusted deposit insurance premia. As is apparent in (23), to fully offset the moral hazard implicit in insured dollar deposits, and hence obviate the need for bank capital, the insurance premium differential should equal: $P\left(\delta^{M}\right)-$ $\frac{\delta^{*}-\delta^{M}(1)}{2 \delta^{*}}\left(k^{C}+\rho^{*}-r_{D}^{*}\right)$, which can also be expressed as $\frac{\delta^{*}-\delta^{M}(1)}{2 \delta^{*}}\left[r_{D}^{*}+\frac{\delta^{*}+\delta^{M}(1)}{2}-\right.$ $\left.\left(\rho^{*}+k^{C}\right)\right]$. In this last form, it is clear that the premia on dollar deposits would cover the expected benefits of fully ensured returns (including valuation gains) in the event of a depreciation when these payments exceed the residual value of the corresponding assets. Thus, setting aside liquidation costs, the deposit insurance dollar premium would be fair and would eliminate moral hazard. Indeed, by affecting the dollar-peso spread, it would eliminate the return differential in favor of dollars in the event of no devaluation, thereby inducing even banks with no capital to intermediate in pesos rather than in dollars. In addition, currency specific deposit insurance premia are arguably more transparent than a bank's overall regulatory capital ratio and hence potentially less subject to regulatory forbearance. This may make them a useful tool to influence ex ante dollarization in environments where it is difficult to ensure that capital requirements are met

\footnotetext{
${ }^{41}$ This point serves to highlight some of the limitations of capital requirements when capital is either non-enforceable or non-monitorable.
} 
and where it is unclear that banks would lose their capital in the event of a devaluation and banking crisis.

However, risk-adjusted insurance premia also face important limitations. First, a bank's capital serves to protect the bank's existence and all of the bank's creditors. Instead, deposit insurance generally is aimed to protect only one class of a bank's creditors, the smaller depositors. Second, if high premia are only payable on a small dollar deposits, banks may adopt higher levels of dollarization elsewhere in their balance sheets to compensate. ${ }^{42}$

In countries where risk management and supervisory capabilities are limited, prudential regulations limiting dollar loans to the borrowers that are less likely to incur currency mismatches, may constitute a second best but more practical alternative to a comprehensive, more finely tuned, risk-based approach. However, where dollarization is already very high, this policy option is clearly not available.

In all cases, a tightening of prudential norms on dollars on-shore (or limits on dollar lending) is likely to promote regulatory arbitrage and may lead to at least as great an increase in offshore (dollar) intermediation than on-shore peso intermediation. If offshore deposits are held in international banks, the cost of bank bail outs would be lower, hence reducing $\delta^{M}$. But if offshore deposits are held in the offshore subsidiaries of national banks and then lent back to local corporates, the authorities may end up having to bail out those banks with the same costs as if they were onshore. This underlines the need for consolidated supervision of offshore entities under a uniform regulatory framework. Without it, regulatory arbitrage could substantially erode the effectiveness of any prudential tightening and de dollarization would not result.

\subsection{Strategic issues}

\subsubsection{Should the supervisory authorities coordinate with the mone- tary authorities?}

In view of the diversity of factors underlying dollarization and the multiple equilibria resulting from regime endogeneity, a policy agenda to reduce dollarization and its attendant risks would need to include a broad menu of concerted actions going well beyond prudential reforms. Indeed as we have argued above, in some cases prudential actions on their own may backfire. In this context, there would seem to be good arguments in favor of policy coordination, i.e., the monetary and supervisory authorities agreeing on a gradual reduction of the devaluation threshold $\delta^{M}$. By reducing the perceived risk associated with peso loans, this could facilitate dedollarization, in turn reducing fear of floating. The argument could thus be made that forward looking policy coordination could support a self-fulfilling gradual dedollarization process.

\footnotetext{
${ }^{42}$ If deposit insurance premia are to be priced correctly, they also need to reflect the particular risks a bank is taking. Making them currency sensitive would add to this complexity. This is a general problem and frequently deposit insurance premia may only take certain broad dimensions of bank risk into account. The proposal here is that perhaps currency composition should be one of them.
} 
However, such an approach would be fraught with dangers. Imposing on banks risk criteria based on one possible future monetary policy, and not on a distribution of potential future monetary policies (including past and not necessarily attractive ones), could backfire. Should market participants remain skeptical and continue to transact in dollars, fear of floating would continue and the risk criteria imposed by the supervisor could directly conflict with the risks banks and borrowers actually face. Thus, such an approach could conflict with the goal of ensuring the continued soundness of the financial system and would call the independence of the supervisor into question.

Instead, there are good arguments for safeguarding the independence of the supervisor and allowing prudential risk assessment to mirror that of banks and the market in general, i.e., remain skeptical. In addition to limiting the financial system's exposure to risk, this would also help limit the risk that $\delta_{v a r}$ be misinterpreted by banks (and the public at large) as providing a signal of $\delta^{M}$, which would further restrict the monetary authorities' margin of action. Instead, openly decoupling supervisory benchmarks from monetary benchmarks (i.e., clearly dissociating $\delta_{v a r}$ from $\delta^{M}$ ), will enhance monetary independence and, as discussed above, limit fear of floating provided $\delta_{v a r}>\delta^{M}$.

Consistent with this approach, prudential reform should be allowed to proceed independently of the rest of the policy agenda. The basic guiding principle should be that all the risks banks face in the current macroeconomic environment should be similarly identified and properly internalized, with a tolerance range that is acceptable to the supervisor. Thus, when banks' level of protection against devaluations needs to be raised, this should be corrected at the supervisory level (by asking banks to use a higher $\delta_{v a r}$ ) or at the regulatory level (by introducing risk-based prudential norms that will facilitate the internalization of risks).

At the same time, banks' exposure to interest rate and output risks incurred on peso loans (a function of $\delta^{M}$ ) should be calibrated based on past observations, rather than policy announcements. If banks move to greater peso or MVP contracting but the distribution of possible future monetary policies continues to include fear of floating it is important to note that capital requirements may well have to rise inititially and not fall. Only over time as the degree of dollarization in actuality falls and the likelihood of fear of floating subsides, would peso and MVP contracting imply lower capital requirements.

Clearly, such an approach offers no guarantee of achieving de-dollarization on its own. When the alternatives to the dollar are too risky under the current macroeconomic environment, banks may not move. Thus, additional, non riskbased approaches may be called for. However, because the externality that leads to fear of floating is macroeconomic in nature (i.e., it reflects an inadequate assessment of the risks and welfare costs faced by the economy as a whole, rather than the risks faced by each lender), such measures should be thought out and announced by a wider body than the supervisory authority. Ideally, they should be introduced by the monetary authority or the government at large, rather than by the supervisory authorities. For example, a tax-subsidy scheme as the one sketched out above should be introduced based on reserve requirements (a monetary instrument), rather than liquidity requirements (a 
prudential instrument). When non risk-based instruments are introduced by the supervisor, such measures should be clearly differentiated and their motivation explained.

\subsubsection{When is full de jure dollarization preferable?}

Highly dollarized countries where the transition costs to a non-dollarized economy are considered prohibitively expensive may consider increasing their commitment to no devaluation, such that $\delta^{M}(1)>\delta^{*}$. In particular, the monetary authorities could make the switch to full de jure dollarization. Provided this is considered to be irreversible, the economy would no longer be subjected to currency-related credit risk. However, abandoning a dual currency system could be welfare inferior. If full dollarization implied no other changes, this would clearly be true in our model when the full de facto dollarization equilibrium is such that $\delta^{M}(1)<\delta^{*}$. Since the welfare cost of an overvalued exchange rate exceeds the welfare cost of banking and corporate crises, it is optimal by construction to retain some exchange rate flexibility to respond to major shocks. Moreover, a fully dollarized economy could be more exposed to output-induced credit risk than an MVP economy. Indeed, this would be the case, as in Figure 5 , when $\delta^{*}-\widehat{\delta}^{C}(1)>\delta^{M}(\widehat{\nu})-\widehat{\delta}^{C}(\widehat{\nu}) \geq 0$.

Several caveats are in order, however. First, most dollarizers would suggest that prices become more flexible under full dollarization and this might be reflected as a change in the parameter $\mu$ - the cost of an overvalued exchange rate. Second, if the economy was stuck in a very poor equilibrium where the authorities had no intention of devaluing but the public remained unconvinced, then relative to that equilibrium, full dollarization would generally be preferred. Finally, we do not consider pure liquidity or other currency crises not related to the real exchange rate (contagion, political crises and the like). If such an "unwelcome" devaluation was considered a significant threat, the benefits of full dollarization would also increase.

\section{Conclusions}

This paper has identified a set of specific factors that may lead to de facto dollarization. These include macroeconomic hedging stemming from investor risk aversion, market imperfections, an attempt by lenders and borrowers to reduce liquidation costs given a particular monetary policy, multiple creditor coordination problems, and finally moral hazard due to deposit insurance or other guarantees in a dollarized financial system. In addition, the paper identified a general feedback from the level of dollarization to monetary policy that results from an underlying lack of monetary credibility. The monetary authorities' inability to precommit reinforces de facto dollarization and gives rise to severe problems of multiple equilibria. In particular, fear of floating induces lenders and borrowers to transact in dollars to reduce expected liquidation costs, in turn exacerbating fear of floating. A highly dollarized financial system may 
thus be associated with high fear of floating and infrequent but devastating devaluations. The multiple equilibria aspect of the model suggests that some unlucky countries will get stuck in such an equilibrium whereas others may escape dollarization completely. This may explain the very different structures of dollarization, as reviewed elsewhere in this project, even within the Latin American region.

The complex and quite subtle nature of de facto dollarization implies that the regulatory response must be carefully considered. When moral hazard is an issue, a good case can be made for internalizing up-front the risks associated with dollar loans to non dollar earning borrowers, within a sufficient range of possible shocks. Such a tightening of the supervisory or regulatory framework should proceed irrespective of whether broader policy reforms are simultaneously adopted in other fronts to limit dollarization. It can take the form of higher provisions, higher capital adequacy requirements on dollar loans, or higher riskadjusted insurance premia on dollar deposits. The choice of instruments will depend in part on the openness and efficiency of the market for bank capital, as well as the credibility of pledges by regulators not to extend after-the-fact regulatory forbearance. It is also affected by the extent to which the regulator wishes to fine tune its response and allow banks to address problems on a caseby-case basis. The tightening of prudential norms will generally need to be accompanied by a strengthening of banking supervision. In many cases, the approach might be strictly supervisory (i.e., making sure that banks correctly assess currency-induced credit risks under the current regulatory framework but with parameters provided by the supervisor), rather than regulatory. To limit the scope for regulatory arbitrage, the reach of the supervisory and regulatory framework needs to be extended beyond the onshore banking intermediaries.

There is no guarantee, however, that prudential reform alone will suffice to achieve dedollarization. Moreover, absent changes in monetary policy, changes in prudential norms that go beyond the internalization of risk and aim at directly inducing dedollarization run the risk of further boosting the dollar either onshore or offshore (banks with higher capital have more to lose by lending in pesos) and not reducing fear of floating at all.

For serious de-dollarizers, a comprehensive, well-coordinated, step-by-step, policy response is thus likely to be needed to break up the dollarization "Gordian knot" and exit the bad equilibria. ${ }^{43}$ This should include measures to enhance the credibility of monetary policy (such as a strengthening of its independence perhaps through a more transparent and hence accountable regime for monetary policy), market enhancements (such as the development of priceindexed contracts to provide a potentially more attractive alternative to dollar and a bridge towards the peso), institutional reforms (such as revisions of the bankruptcy code), and market infrastructure reforms (such as payments system improvements). In the most extreme cases, measures aimed at directly inducing de-dollarization, such as (increasingly) binding limits on dollar lending, could

\footnotetext{
${ }^{43}$ The need for a comprehensive approach in dealing with dollarization is also emphasized by Goldstein and Turner (2003) and Levy Yeyati and Fernandez Arias (this volume).
} 
help accelerate the shift to the peso. However, highly dollarized countries may be on a knife edge. If monetary policy credibility is not sufficiently enhanced, the risks of shifting towards alternative (and more risky) channels of dollar intermediation are high.

\section{$5 \quad$ References}

Aghion, P, P. Bacchetta and A. Banerjee (2001) "A Corporate Balance Sheet Approach to Currency Crises", CEPR working paper, No. 2083.

Broda, C. and E. Levy Yeyati (2003) "Endogenous deposit dollarization", Federal reserve Bank of New York, Staff Report, No.160.

Burnside, C., Eichenbaum B. and S. Rebelo (2001) "Hedging and Financial Fragility in Fixed Exchange Rate Regimes", European Economic Review, Vol. 45 (June), pp. 1151-1193.

Caballero, R. and A. Krishnamurty (2003) "Excessive Dollar Debt: Financial Development and Underinsurance", Journal of Finance, Vol. LVIII, No. 2 (April), pp. 867-893.

Calvo, G. and P. Guidotti (1990) "Credibility and Nominal Debt IMF: Exploring the Role of Maturity in Managing Inflation", IMF Staff Papers, 37, 3 (Sept) pp 612-635.

Catao, L. and M. Terrones, M. (2000) "Determinants of Dollarization - The Banking Side", IMF WP/00/146

Cespedes, L., Chang, R. and A. Velasco. (2000) "Balance sheets and exchange rate policy", NBER WP No 7840.

Chamon, M.(2001) "Foreign Currency Denomination of Foreign Debt: Has the Original Sin Been Forgiven but not Forgotten?", Mimeo, Harvard University.

Chamon, M. and R. Hausmann (2002) "Why Do Countries Borrow the Way they Borrow?", Mimeo, Harvard University.

Chang, R. and A. Velasco (2003) "Endogenous Dollarization and Monetary Policy", Presented at the Conference on "Financial Dedollarization: Policy Options", InterAmerican Development Bank, Washington DC.

Cowan, K. and Q.T. Do (2003) "Financial Dollarization and Central Bank Crediblity", mimeo, InterAmerican Development Bank.

De Nicolo, G., Honohan, P. and A. Ize (2003) "Dollarization of the Banking System: Good or Bad?", IMF WP/03/146.

Dooley, M. (2000) "A Model of Crisis in Emerging Markets", The Economic Journal, Vol. 110, No. 460, pp. 256-272.

Freixas, X. and J.C. Rochet (1999) Microeconomics of Banking, MIT Press, Cambridge, Massachusetts.

Fuentes, R., A. Jara, K. Schmidt-Hebbel and M. Tapia (2003) "La Nominalizacion de la Politica Monetaria en Chile", Economia Chilena, Vol. 6 No. 2 (August).

Gale, D. and X. Vives (2002) "Dollarization, Bailouts, and the Stability of the Banking System", Quarterly Journal of Economics (May), pp. 467-502. 
Goldstein, M. and P. Turner, 2003 "Currency Mismatching in Emerging Economies", Bank for International Settlements, Basel.

Ize, A. and E. Levy Yeyati (1998) "Dollarization of Financial Intermediation; Causes and Policy Implications", IMF WP/98/28. Revised as "Financial Dollarization", Journal of International Economics, 59 (2003), pp. 323-347.

Ize, A. and E. Parrado (2002) "Dollarization, Monetary Policy, and the Passthrough", IMF WP/02/188.

Jeanne, O. (2002) "Why Do Emerging Economies Borrow in Foreign Currency? ", Presented at the Conference on "Currency And Maturity Matchmaking: Redeeming Debt From Original Sin", InterAmerican Development Bank, Washington DC.

Kim, D and A. Santomero (1980) "Risk in banking and capital regulation", Journal of Finance 43(5) pp 1219-33.

Levy Yeyati, E. and E. Fernandez Arias (2003) "Financial Dedollarization; Where do we Stand?", Presented at the Conference on "Financial Dedollarization: Policy Options", InterAmerican Development Bank, Washington DC.

McKinnon, R. and H. Pill (1999) "Credible Economic Liberalizations and Overborrowing", American Economic Review, Vol. 87:2, pp. 189-193.

Miller, M and J. Stiglitz (2000) "Bankruptcy Protection Against Macroeconomic Shocks: The Case for a Super Chapter 11" Address to the Royal Economic Society Conference, mimeo, University of Warwick.

Rochet, J.C. (1992) "Capital Requirements and the Behaviour of Commercial Banks", European Economic Review 36(5) pp 1137-70.

Schneider, M. and A. Tornell (2000), "Balance Sheet Effects, Bail Out Guarantees, and Financial Crises", Mimeo, UCLA.

\section{Appendices}

\subsection{Appendix I: The default thresholds}

To express the threshold corporate sector conditions in a structural form, we need to express $R$ as a function of $\lambda$. Let us first consider the high dollarization thresholds $\delta^{C}$ and $\delta^{B}$. Corporates default with the devaluation, so that banks' ex-ante zero excess profits condition can be expressed as:

$$
\begin{gathered}
\frac{1}{2 \delta^{*}} \int_{-\delta^{*}}^{\delta^{M}}(1) R \widehat{d \delta}+\frac{1}{2 \delta^{*}} \int_{\delta^{M}(1)}^{\delta^{*}}\left[\rho^{*}-\varpi^{C}+k^{C}\right] \widehat{d \delta}-\frac{1}{2 \delta^{*}} \int_{-\delta^{*}}^{\delta^{*}} r \widehat{d \delta}=r_{k} k^{B}, \\
R=\frac{2 \delta^{*}}{\delta^{M}(1)+\delta^{*}}\left(r+r_{k} k^{B}\right)-\frac{\delta^{*}-\delta^{M}(1)}{\delta^{M}(1)+\delta^{*}}\left[\rho^{*}-\varpi^{C}+k^{C}\right] .
\end{gathered}
$$

where, using (37):

$$
r=r_{D}^{*}+\frac{1-\lambda}{1-\widehat{\nu}} P\left(\delta^{M}\right)-\frac{(1-\lambda)(\lambda-\widehat{\nu})}{1-\widehat{\nu}} c V\left(\delta^{M}\right) .
$$

Substituting (31) in (1a) leads to: 


$$
\delta^{C}=\frac{2 \delta^{*}}{\delta^{*}+\delta^{M}} \frac{1-\widehat{\nu}}{\lambda-\widehat{\nu}}\left[\rho^{*}+k^{C}-r-r_{k} k^{B}-\frac{\delta^{*}-\delta^{M}}{2 \delta^{*}} \varpi^{C}\right] .
$$

It can be checked from this equation that $\partial \delta^{C} / \partial \lambda<0$ if $c$ is moderate and $\delta^{C}>\frac{\delta^{*}-\delta^{M}}{2}$, which should be verified when $\delta^{*}-\delta^{M}$ is small, i.e., in the limit peso problem case. The same condition ensures that banks' high dollarization threshold also has a negative slope.

Let us now consider the low dollarization thresholds $\widehat{\delta}^{C}$ and $\widehat{\delta}^{B}$. Corporates default in the absence of a devaluation, so that banks' ex-ante zero excess profits condition may be expressed as:

$$
\frac{1}{2 \delta^{*}} \int_{-\delta^{*}}^{\widehat{\delta}^{C}} R d \widehat{\delta}+\frac{1}{2 \delta^{*}} \int_{\widehat{\delta}^{C}}^{\delta^{M}(0)}\left[\rho^{*}-\varpi^{C}-\mu \widehat{\delta}+k^{C}\right] d \widehat{\delta}+\frac{1}{2 \delta^{*}} \int_{\delta^{M}(0)}^{\delta^{*}} R d \widehat{d}-\frac{1}{2 \delta^{*}} \int_{-\delta^{*}}^{\delta^{*}} r d \widehat{\delta}=
$$

Using this condition, (1a) leads to the following expression:

$$
\widehat{\delta}^{C}=\frac{\rho^{*}+k^{C}-r-r_{k} k^{B}-\left(\varpi^{C}+\mu \delta^{M}\right) \delta^{M} / 2 \delta^{*}}{\mu-\left(\varpi^{C}+\mu \delta^{M}\right) / 2 \delta^{*}} .
$$

where $r$ is given by (32) and $\delta^{M}$ by the various expressions given in the text. For $c$ small (i.e., when risk aversion is limited) and assuming that changes in $r_{k} k^{B}$ can be safely ignored compared to changes $r$ (this should be the case if both $k^{B}$ and $r_{k}$ are small), $\partial r / \partial \lambda<0$ as an increase in dollarization reduces the impact of the peso problem on the average cost of funds (both through a direct currency composition effect and through a reduction in $P\left(\delta^{M}\right)$ ). It then follows that $\partial \widehat{\delta}^{C} / \partial \lambda>0$ if $\delta^{M}$ follows any of the patterns described in Figure 1; i.e., if it is constant and $\mu \delta^{*}>\varpi^{C}$ (the maximum possible output cost of an overvalued exchange rate exceeds the corporate liquidation costs; we assume this to be the case); or if $\delta^{M}$ follows $\widehat{\delta}^{C}$; or if it follows $\widehat{\delta}^{B}$ but $\widehat{\delta}^{B}$ runs broadly parallel to $\widehat{\delta}^{C}$. On the other hand, when $c$ is large, $\partial r / \partial \lambda$ continues to be negative (hence, $\partial \widehat{\delta}^{C} / \partial \lambda$ continues to be positive) over the range $\lambda \in[0, \widehat{\nu}]$. However, signs can become inverted in the high dollarization range as risk aversion may eventually raise the cost of funds as the currency composition increasingly deviates from MVP. A similar condition holds for $\widehat{\delta}^{B}$ and similar reasoning leads to the same conclusions regarding the shape of this schedule.

\subsection{Appendix II: The MVP equilibrium}

Depositors' expected utility can be written:

$$
\begin{aligned}
& U=\frac{(1-\lambda)}{2 \delta^{*}}\left[\int_{-\delta^{*}}^{0}\left(r_{p}-\widehat{\delta}\right) d \widehat{\delta}+\int_{0}^{\delta^{M}} r_{P} d \widehat{\delta}+\int_{\delta^{M}}^{\delta^{*}}\left(r_{P}-\frac{\widehat{\nu}}{1-\widehat{\nu}} \widehat{\delta}\right) d \widehat{\delta}\right]+\frac{\lambda}{2 \delta^{*}}\left[\int _ { - \delta ^ { * } } ^ { 0 } \left(r_{D}^{*}-\right.\right. \\
& \left.\widehat{\delta}) d \widehat{\delta}+\int_{0}^{\delta^{M}} r_{D} \widehat{d} \widehat{\delta}+\int_{\delta^{M}}^{\delta^{*}}\left(r_{D}+\widehat{\delta}\right) d \widehat{\delta}\right]-\frac{c}{2} \operatorname{Var}(r) \\
& \quad \text { or: } \\
& \quad U=(1-\lambda) r_{P}+\lambda r_{D}+\frac{(\lambda-\widehat{\widehat{\nu}})}{1-\widehat{\nu}} P\left(\delta^{M}\right)-\frac{\delta^{*}}{4}-\frac{c}{2} \operatorname{Var}(r), \\
& \quad \text { where: }
\end{aligned}
$$




$$
P\left(\delta^{M}\right)=\frac{\delta^{* 2}-\delta^{M^{2}}}{4 \delta^{*}}=\frac{\delta^{*}-\delta^{M}}{2 \delta^{*}} \frac{\delta^{*}+\delta^{M}}{2}
$$

is the average expected real depreciation.

The deviations of returns from the mean in the case of a positive terms of trade shock, negative shock/no devaluation and negative shock/devaluation are, respectively:

$-\frac{(\lambda-v)}{1-\widehat{\nu}} P\left(\delta^{M}\right)+\frac{\delta^{*}}{4}-\delta,-\frac{(\lambda-v)}{1-\widehat{\nu}} P\left(\delta^{M}\right)+\frac{\delta^{*}}{4}$ and $\frac{(\lambda-v)}{1-\widehat{\nu}}\left[\delta-P\left(\delta^{M}\right)\right]+\frac{\delta^{*}}{4}$,

which leads to:

$\operatorname{Var}(r)=\frac{(\lambda-v)^{2}}{(1-\widehat{\nu})^{2}} V\left(\delta^{M}\right)-\frac{19}{64} \delta^{* 2}$,

where:

$V\left(\delta^{M}\right)=\left[\left(\delta^{M}+\delta^{*}\right) P\left(\delta^{M}\right)^{2}+\left(\delta^{*}-P\left(\delta^{M}\right)\right)^{3} / 3-\left(\delta^{M}-P\left(\delta^{M}\right)\right)^{3} / 3\right] / 2 \delta^{*}$

is the variance of the distribution of real depreciations.

Thus, the first order condition can be written:

$$
r_{D}^{*}-r_{P}+\frac{1}{(1-\widehat{\nu})} P\left(\delta^{M}\right)-c \frac{(\lambda-\widehat{\nu})}{(1-\widehat{\nu})^{2}} V\left(\delta^{M}\right)=0,
$$

from which (10) in the text immediately follows.

\subsection{Appendix III: Default equilibria}

Consider the case of real default dollarization and no fear of floating. From (37) it follows that the risk premium on the dollar deposit rate when the economy is fully dollarized is: $r_{D}^{*}-r^{*}+P\left(\delta^{M}\right)=c V\left(\delta^{M}\right)$. The joint expected profits of borrowers and banks on dollar loans are: $\frac{1}{2 \delta^{*}}\left[\int_{-\delta^{*}}^{0}\left(\rho^{*}-r_{D}^{*}-\widehat{\delta}\right) d \widehat{\delta}+\int_{0}^{\delta^{M}}\left(\rho^{*}-\right.\right.$ $\left.\left.\mu \widehat{\delta}-r_{D}^{*}\right) d \widehat{\delta}+\int_{\delta^{M}}^{\delta^{*}}\left(\rho^{*}-\varpi^{C}-r_{D}^{*}-\widehat{\delta}\right) d \widehat{\delta}\right]$. Instead, their joint profits on MVP loans are: $\frac{1}{2 \delta^{*}}\left[\int_{-\delta^{*}}^{0}\left(\rho^{*}-r^{*}-\widehat{\delta}\right) d \widehat{\delta}+\int_{0}^{\widehat{\delta}^{C}}\left(\rho^{*}-\mu \delta-r^{*}\right) d \widehat{\delta}+\int_{\widehat{\delta}^{C}}^{\delta^{M}}\left(\rho^{*}-\mu \widehat{\delta}-\right.\right.$ $\left.\left.\varpi^{C}-r^{*}\right) d \widehat{\delta}+\int_{\delta^{M}}^{\delta^{*}}\left(\rho^{*}-r^{*}\right) d \widehat{\delta}\right]$. The difference between these two expressions is: $\frac{1}{2 \delta^{*}}\left[\int_{-\delta^{*}}^{\delta^{*}}\left(r_{D}^{*}-r^{*}\right) d \widehat{\delta}-\int_{\delta^{M}}^{\delta^{*}}\left(\varpi^{C}+\widehat{\delta}\right) d \widehat{d}+\int_{\widehat{\delta}^{C}}^{\delta^{M}} \varpi^{C} d \widehat{\delta}\right]$

Using the expression above for the dollar risk premium, this last expression can be rewritten as: $\left[P\left(\delta^{M}\right)-\int_{\delta^{M}(1)}^{\delta^{*}} \widehat{\delta} d \widehat{\delta}\right]-c V\left(\delta^{M}\right)+\varpi^{C}\left[\int_{\widehat{\delta}^{C}}^{\delta^{M}} d \widehat{\delta}-\int_{\delta^{M}}^{\delta^{*}} d \widehat{\delta}\right]$. The first term between brackets is zero by definition. Hence, the difference in returns reduces to the difference in expected probabilities of default, adjusted for the risk premium: $\varpi^{C}\left[\int_{\widehat{\delta}^{C}}^{\delta^{M}} d \widehat{\delta}-\int_{\delta^{M}}^{\delta^{*}} d \widehat{\delta}\right]-c V\left(\delta^{M}\right)$.

\subsection{Appendix IV: Moral hazard dollarization}

Take first the case of the full dollarization equilibrium. For it to be stable, the expected joint dollar returns of a marginal bank (and its borrowers) must be 
higher than its expected MVP returns. In the dollar equilibrium, the expected returns of a marginal bank (and its borrowers) are:

$$
\frac{1}{2 \delta^{*}}\left[\int_{-\delta^{*}}^{0}\left(\rho^{*}-r_{D}^{*}-\widehat{\delta}\right) d \widehat{\delta}+\int_{0}^{\delta^{M}(1)}\left(\rho^{*}-\mu \widehat{\delta}-r_{D}^{*}\right) d \widehat{\delta}-\int_{\delta^{M}(1)}^{\delta^{*}}\left(k^{C}+k_{D}^{B}\right) d \widehat{\delta}\right]=r_{k}\left(k_{D}^{B}+k^{C}\right)
$$

where $k_{D}^{B}$ and $k_{P}^{B}$ are differentiated capital requirements on dollar and peso loans, respectively. For the dollar equilibrium to be stable, the excess returns of an isolated bank (and its borrowers) switching to MVP intermediation should be negative, which can be written:

$$
\frac{1}{2 \delta^{*}}\left[\int_{-\delta^{*}}^{0}\left(\rho^{*}-r^{*}-\widehat{\delta}\right) d \widehat{\delta}+\int_{0}^{\delta^{M}(1)}\left(\rho^{*}-\mu \widehat{\delta}-r^{*}\right) d \widehat{\delta}+\int_{\delta^{M}(1)}^{\delta^{*}}\left(\rho^{*}-r^{*}\right) d \widehat{\delta}\right]<r_{k}\left(k_{m}^{B}+k^{C}\right),
$$

Subtracting (39) from (38) leads to: $\frac{1}{2 \delta^{*}}\left[\int_{-\delta^{*}}^{\delta^{*}}\left(r^{*}-r_{D}^{*}\right) d \widehat{\delta}>\int_{\delta^{M}(1)}^{\delta^{*}}\left(k^{C}+k_{D}^{B}+\right.\right.$ $\left.\left.\rho^{*}-r_{D}^{*}\right) \widehat{d \delta}\right]+r_{k}\left(k_{D}^{B}-k_{m}^{B}\right)$, or $r^{*}-r_{D}^{*}>\frac{\delta^{*}-\delta^{M}(1)}{2 \delta^{*}}\left(k^{C}+k^{B}+\rho^{*}-r_{D}^{*}\right)+\left(r_{k}-\right.$ $\left.r^{*}\right)\left(k_{D}^{B}-k_{m}^{B}\right)$. Replacing $r^{*}-r_{D}^{*}$ by $P\left(\delta^{M}(1)\right): P\left(\delta^{M}(1)\right)>\frac{\delta^{*}-\delta^{M}(1)}{2 \delta^{*}}\left(k^{B}+k^{C}+\right.$ $\left.\rho^{*}-r_{D}^{*}\right)+\left(r_{k}-r^{*}\right)\left(k_{D}^{B}-k_{m}^{B}\right)$. Finally, replacing $P\left(\delta^{M}(1)\right)$ by its expression in (35) and simplifying:

$$
k_{D}^{B}+k^{C}+\rho^{*}-r_{D}^{*}<\frac{\delta^{M}(1)+\delta^{*}}{2}-\frac{2 \delta^{*}}{\delta^{*}-\delta^{M}(1)} r_{k}\left(k_{D}^{B}-k_{m}^{B}\right) .
$$

which is the expression shown in the text.

Take now the case of the MVP equilibrium (for simplicity we only develop here the case of uniform capital requirements). For it to be stable, the expected MVP returns of a marginal bank (and its borrowers) should be higher than its dollar returns. In the case where $\delta^{M}(\widehat{\nu})>\delta^{B}(1)$, it is obvious that we would have exactly the same condition as (40) but with the opposite direction and replacing $\delta^{M}(1)$ by $\delta^{M}(\widehat{\nu})$. In the case where $\delta^{M}(\widehat{\nu})<\delta^{B}(1)$ (with uniform capital adequacy requirements):

$$
\begin{gathered}
\frac{1}{2 \delta^{*}}\left[\int_{-\delta^{*}}^{0}\left(\rho^{*}-r^{*}-\widehat{\delta}\right) d \delta+\int_{0}^{\delta^{M}(\widehat{\nu})}\left(\rho^{*}-\mu \widehat{\delta}-r^{*}\right) d \widehat{\delta}+\int_{\delta^{M}(\widehat{\nu})}^{\delta^{*}}\left(\rho^{*}-r^{*}\right) d \widehat{\delta}>\right. \\
\frac{1}{2 \delta^{*}}\left[\int_{-\delta^{*}}^{0}\left(\rho^{*}-r_{D}^{*}-\widehat{\delta}\right) d \widehat{\delta}+\int_{0}^{\delta^{M}(\widehat{\nu})}\left(\rho^{*}-\mu \widehat{\delta}-r_{D}^{*}\right) d \widehat{\delta}+\int_{\delta^{M}(\widehat{\nu})}^{\delta^{B}(1)}\left(\rho^{*}-r_{D}^{*}-\widehat{\delta}\right) d \widehat{\delta}-\right.
\end{gathered}
$$
$\left.\int_{\delta^{B}(1)}^{\delta^{*}}\left(k^{C}+k^{B}\right) d \delta\right]$,

which can be rearranged as: $r^{*}-r_{D}^{*}<\frac{1}{2 \delta^{*}} \int_{\delta^{B}(1)}^{\delta^{*}}\left(k^{C}+k^{B}+\rho^{*}-r_{D}^{*}\right) d \widehat{\delta}+$ $\int_{\delta^{M}(\widehat{\nu})}^{\delta^{B}(1)} \widehat{\delta} \widehat{d \delta}$, leading to: $k_{D}^{B}+k^{C}+\rho^{*}-r_{D}^{*}>\frac{\delta^{B}(1)+\delta^{*}}{2}$. Thus, the general condition can be written:

$$
k^{B}+k^{C}+\rho^{*}-r_{D}^{*}>\frac{\max \left\{\delta^{B}(1), \delta^{M}(\widehat{\nu})\right\}+\delta^{*}}{2}
$$

Consider now the case with risk aversion. In this case, (10) leads, for $\lambda=1$ to: $r^{*}-r_{D}^{*}=P\left(\delta^{M}\right)-c V\left(\delta^{M}\right)$, so that $(40)$ becomes: $k^{B}+k^{C}+\rho^{*}-r_{D}^{*}<$ 
$\frac{\delta^{M}(1)+\delta^{*}}{2}-\frac{2 \delta^{*}}{\delta^{*}-\delta^{M}(1)} c V\left(\delta^{M}(1)\right)$. Thus, for sufficiently high $c^{\prime} s$, there is no scope for a full dollarization equilibrium, even without capital. More generally, for $\lambda<1$ and a given level of capital and profitability, (40) can be reformulated as the following interior equilibrium condition:

$$
\lambda^{D}=\widehat{\nu}+(1-\widehat{\nu}) \frac{1}{c V\left(\delta^{M}(1)\right)} \frac{\delta^{*}-\delta^{M}(1)}{2 \delta^{*}}\left[\frac{\delta^{M}(1)+\delta^{*}}{2}-\left(k^{B}+k^{C}+\rho^{*}-r_{D}^{*}\right)\right] .
$$

For $\lambda>\lambda^{D}$, banks in isolation should migrate towards MVP; inversely, for $\lambda<\lambda^{D}$, banks should dollarize their funding. Hence, $\lambda=\lambda^{D}$ is a stable equilibrium. As $c \rightarrow \infty, \lambda^{D} \rightarrow \widehat{\nu}$.

Finally, consider the case where banks can shorten the dollar. In the full dollarization equilibrium, switching the lending currency from dollars to MVPs would shield the corporates from default, thereby providing the following expected marginal returns to the group: $\frac{1}{2 \delta^{*}}\left[\int_{\delta^{M}(1)}^{\delta^{*}}\left(\rho^{*}-r^{*}-k^{B}\right) d \widehat{\delta}\right]+\int_{\delta^{M}(1)}^{\delta^{*}}\left(k^{C}+\right.$ $\left.\left.k^{B}\right) \widehat{d \delta}\right]=\frac{\delta^{*}-\delta^{M}(1)}{2 \delta^{*}}\left(\rho^{*}+k^{C}-r^{*}\right)>0$.

\subsection{Appendix V: Moral hazard pessification}

For a full peso equilibrium to be stable, the expected joint dollar returns of a marginal bank (and its borrowers) must be higher than its expected MVP returns, which can be written: $\frac{1}{2 \delta^{*}}\left[\int_{-\delta^{*}}^{0}\left(\rho^{*}-r_{P}-\widehat{\delta}\right) d \widehat{\delta}-\int_{0}^{\delta^{M}(0)}\left(k^{C}+k^{B}\right) d \widehat{\delta}+\right.$ $\left.\int_{\delta^{M}(0)}^{\delta^{*}}\left(\rho^{*}-r_{P}+\frac{\widehat{\nu}}{1-\widehat{\nu}} \widehat{\delta}\right) d \widehat{\delta}\right]>\frac{1}{2 \delta^{*}}\left[\int_{-\delta^{*}}^{0}\left(\rho^{*}-r^{*}-\widehat{\delta}\right) d \widehat{\delta}+\int_{0}^{\delta^{M}(0)}\left(\rho^{*}-\mu \widehat{\delta}-r^{*}\right) d \widehat{\delta}+\right.$ $\left.\int_{\delta^{M}(0)}^{\delta^{*}}\left(\rho^{*}-r^{*}\right) d \widehat{\delta}\right]$.

This condition can be rearranged as: $\frac{1}{2 \delta^{*}} \int_{-\delta^{*}}^{\delta^{*}}\left[r^{*}-r_{P}\right] \widehat{d \delta}>\frac{1}{2 \delta^{*}}\left[\int_{0}^{\delta^{M}(0)}\left(k^{C}+\right.\right.$ $\left.\left.k^{B}+\rho^{*}-r_{P}\right) d \widehat{\delta}-\int_{\delta^{M}(0)}^{\delta^{*}} \frac{\widehat{\nu}}{1-\widehat{\nu}} \widehat{\delta} \widehat{d} \delta-\int_{0}^{\delta^{M}(0)} \mu \widehat{\delta} \widehat{d} \widehat{\delta}\right]$,

or: $\quad r^{*}-r_{P}>\left(k^{C}+k^{B}+\rho^{*}-r_{P}\right) \frac{\delta^{M}(0)}{2 \delta^{*}}-\frac{\widehat{v}}{1-\widehat{\nu}} P\left(\delta^{M}(0)\right)-\mu \frac{\delta^{M^{2}}(0)}{2 \delta^{*}}$.

Replacing $r^{*}-r_{P}$ by $-\frac{\widehat{\nu}}{1-\widehat{\nu}} P\left(\delta^{M}(0)\right)$ and $r_{P}$ by $r_{D}^{*}-\frac{1}{1-\widehat{\nu}} P\left(\delta^{M}(0)\right)$ and simplifying leads to:

$$
k^{C}+k^{B}+\rho^{*}-r_{D}^{*}<\mu \frac{\delta^{M}(0)}{2}+\frac{1}{1-\widehat{\nu}} P\left(\delta^{M}(0)\right) .
$$

It is easy to check that this condition will be verified for a non-empty set of capital (and profitability) values if $\widehat{\nu}$ is sufficiently high, i.e., if the pass-through is high (and monetary credibility limited) and there is fear of floating $\left(\delta^{M}(0)<\right.$ $\left.\delta^{M}(\widehat{\nu})\right)$. A similar reasoning focusing on the stability of the MVP equilibrium as compared to the full peso equilibrium leads to a similar expression, with $\delta^{M}(\widehat{\nu})$ replacing $\delta^{M}(0)$. 
Figure 1. The Dollarization Map (with default free MVP lending)

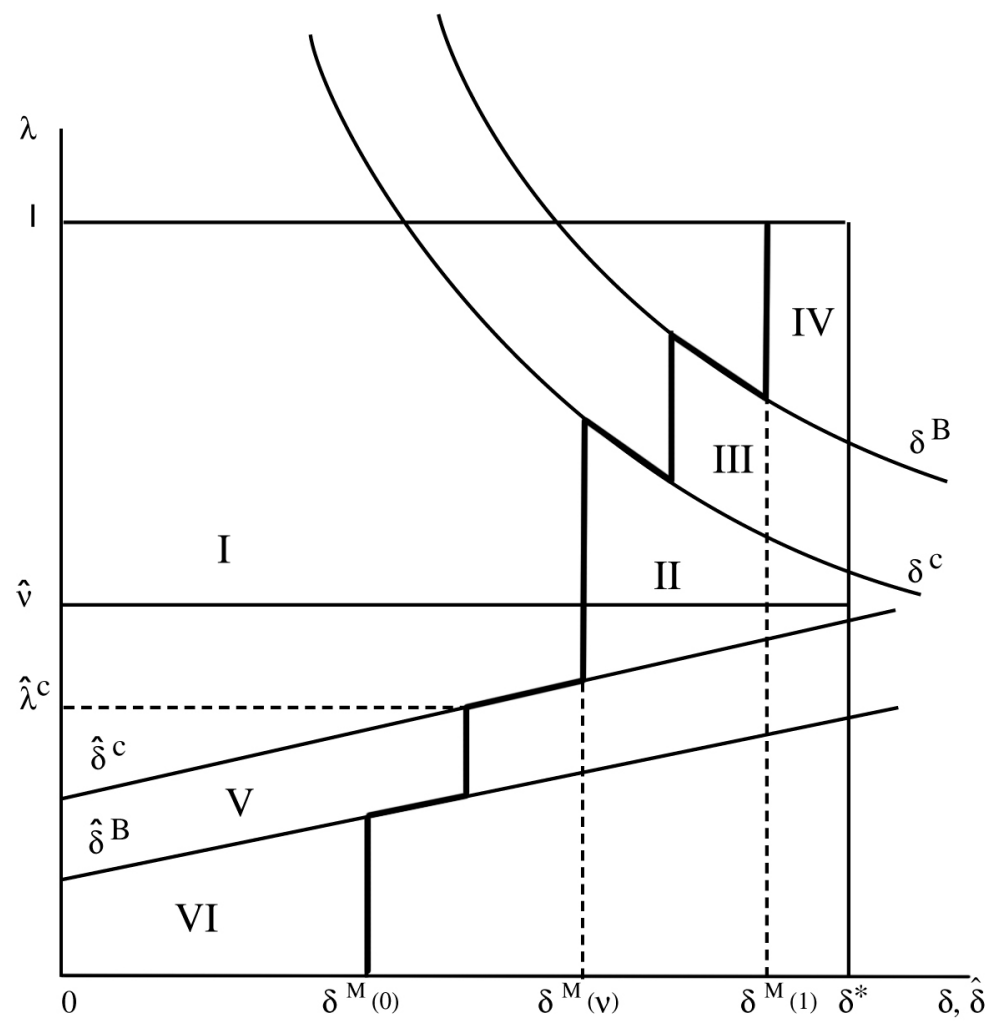


Figure 2. Market Dollarization

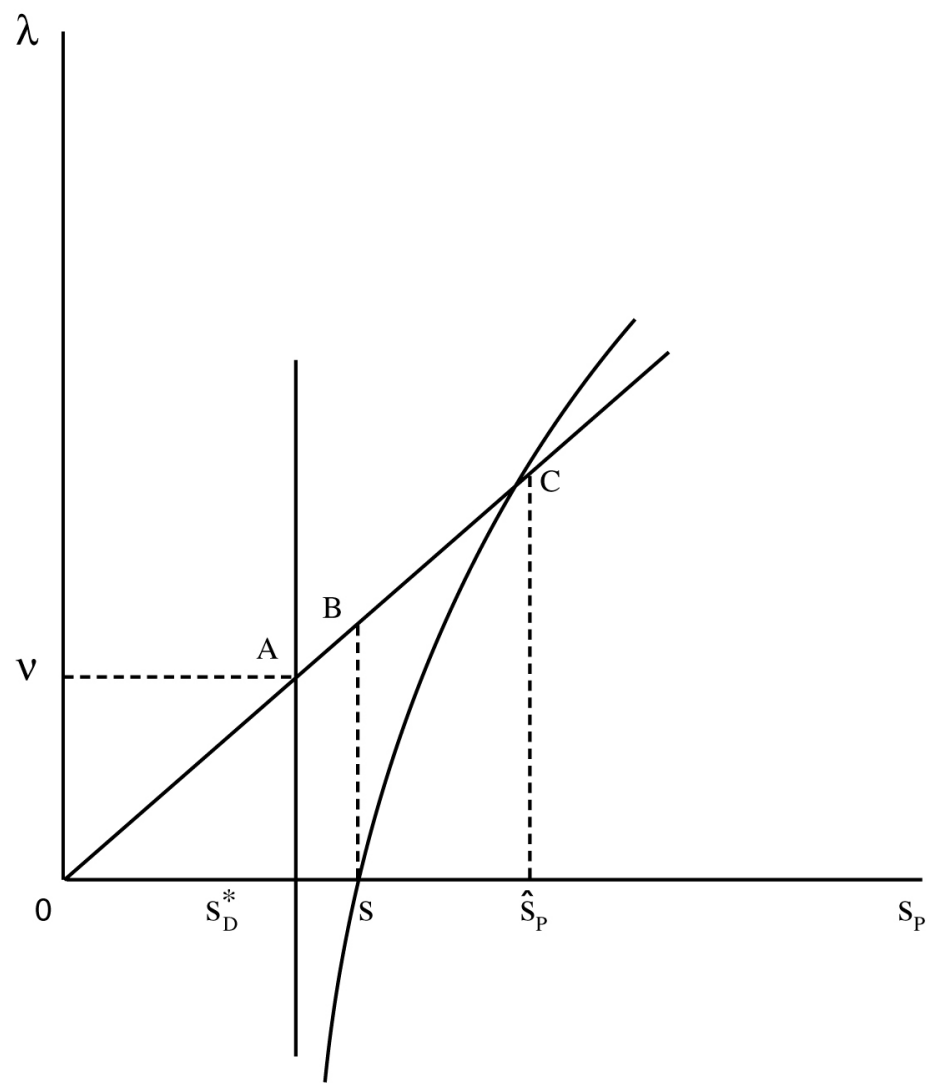


Figure 3: Nominal Default Dollarization

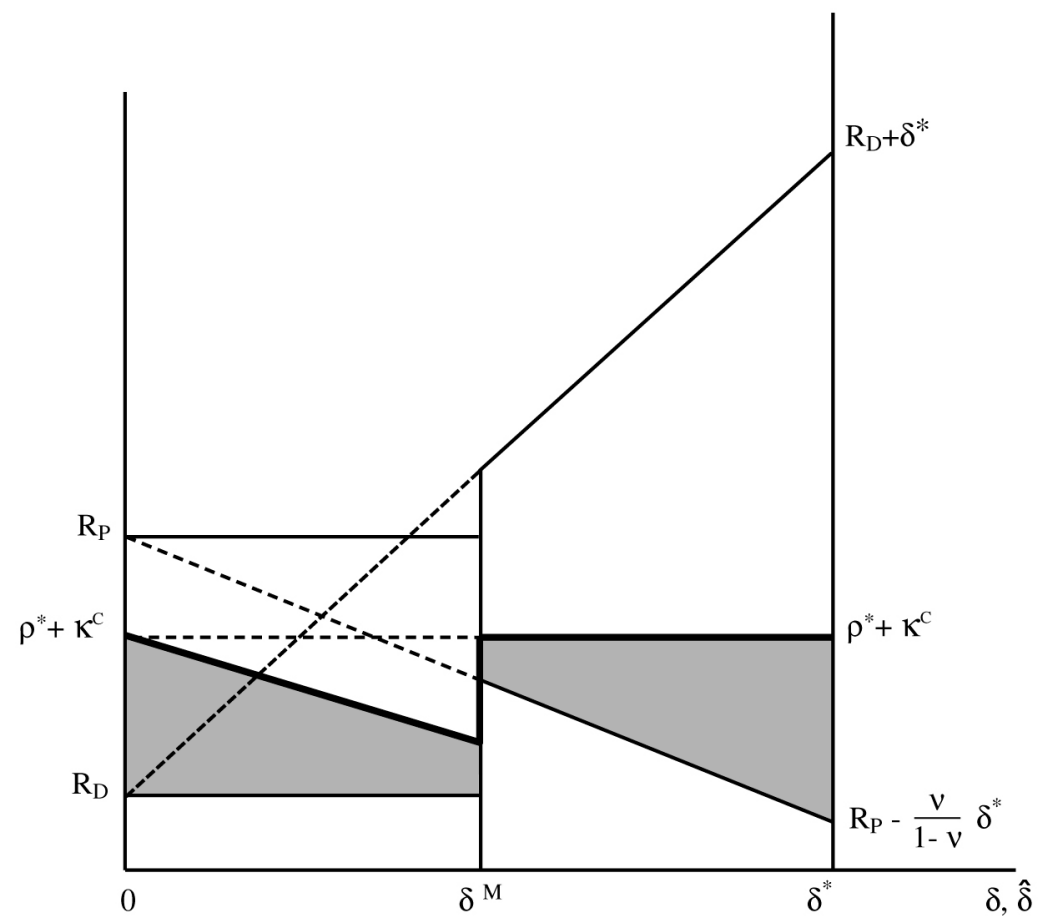


Figure 4: Real Default Dollarization

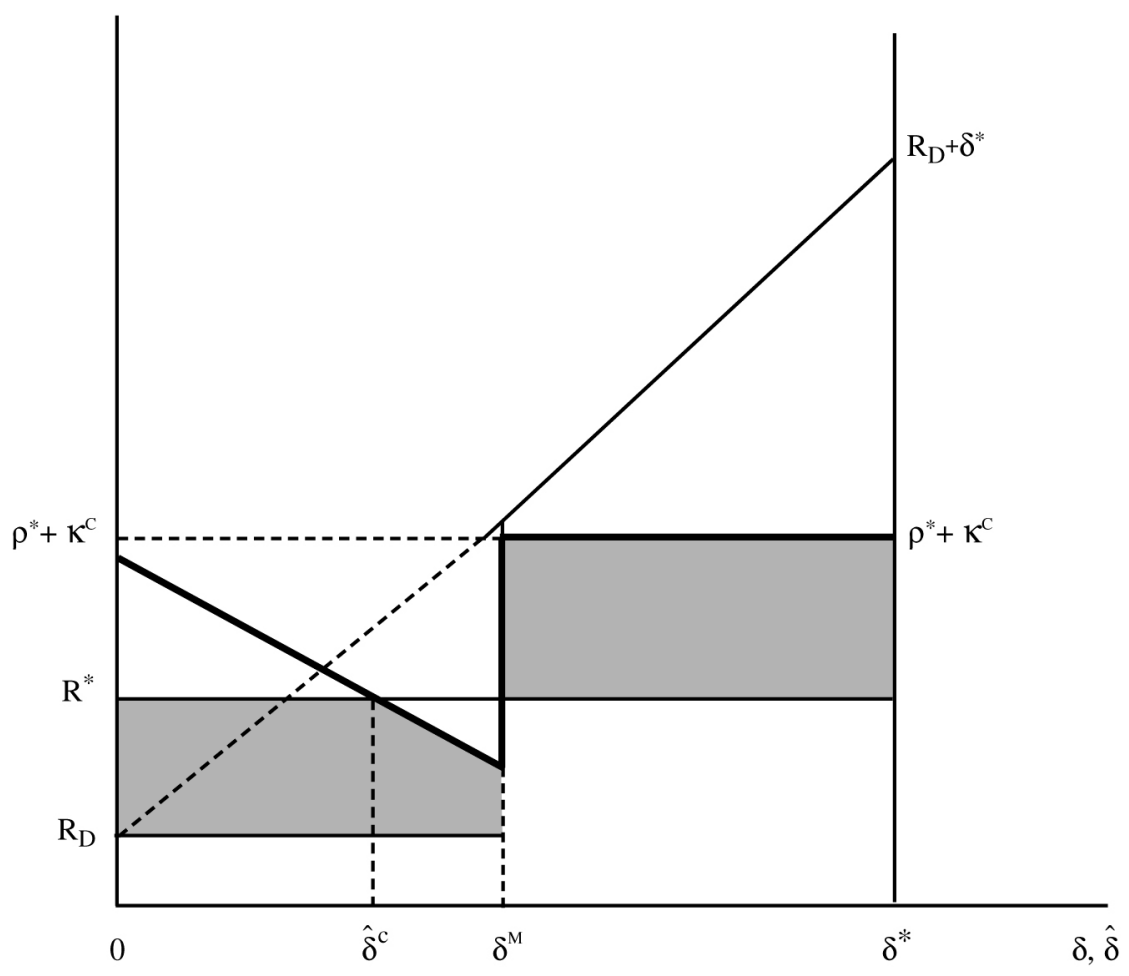


Figure 5: The Dollarization Map (with risky MVP lending)

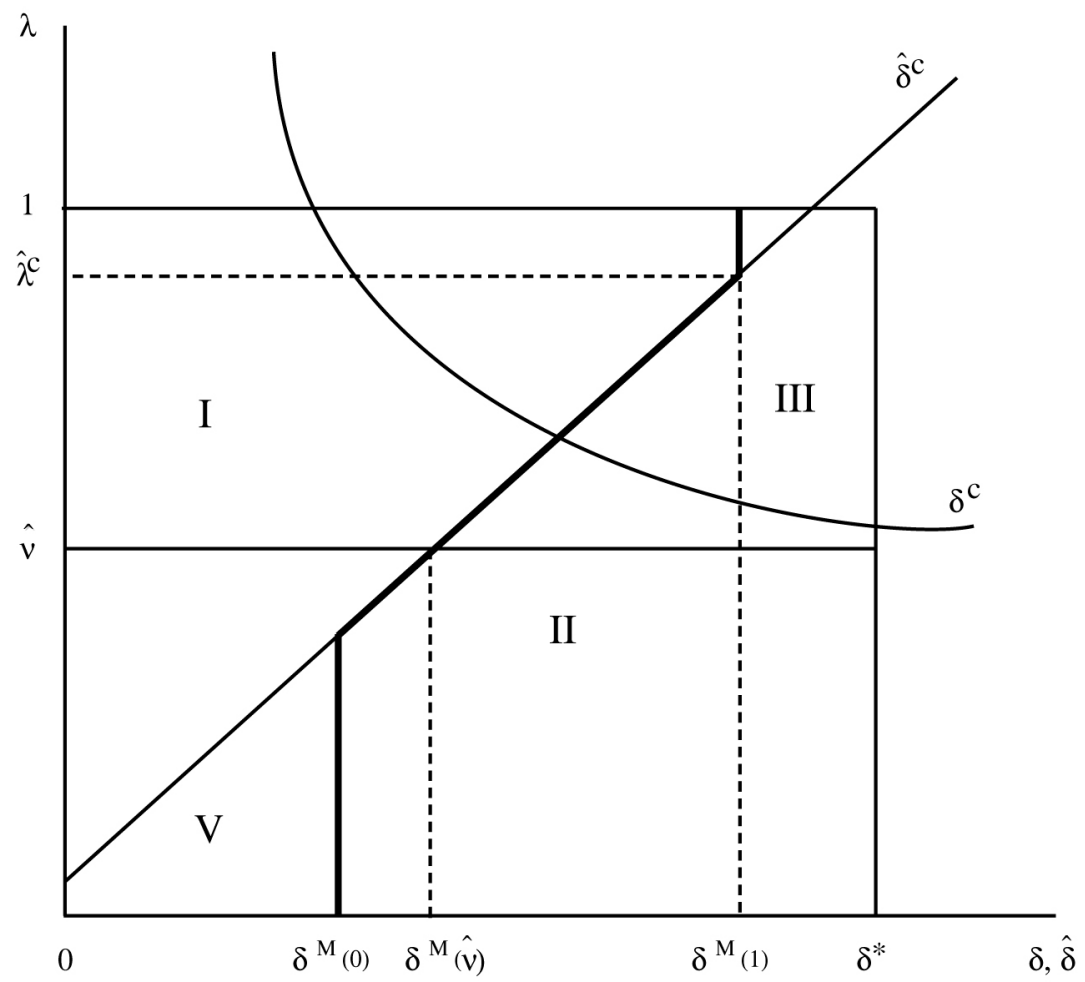

